\title{
The influence of dependability in cloud computing adoption
}

\author{
Chi-hoon Song ${ }^{1}\left[\right.$ [ $\cdot$ Young-woo Sohn ${ }^{1,2}$
}

Accepted: 30 January 2022 / Published online: 28 February 2022

(c) The Author(s) 2022

\begin{abstract}
Cloud computing (CC) has many benefits, so its use has spread rapidly, particularly in the business sector. An important consideration in the acceptance of $\mathrm{CC}$ is whether the CC system is dependable, and it can differ among industry and service type. However, little research has considered the effect of dependability (composed of availability, reliability, security, maintainability) on CC acceptance. Especially, group comparisons between high IT-intensive (Hi-ITi) and low IT-intensive (LoITi) industries have not been reported, nor have comparisons between software-asa-service (SaaS) and platform-as-a-service (PaaS)/infrastructure-as-a-service (IaaS). This study aims to explore how the dependability of $\mathrm{CC}$ affects users' intent to accept it, with focus on how this intent is affected by intensity of IT use (by industry) and by the type of CC service used. To validate the proposed model, this study applied structural equation modeling and conducted multi-group analysis. A total of 230 business managers in South Korea represent the sample for our study. For the full dataset, the three dependability attributes (availability, reliability, security) do not affect the usefulness of $\mathrm{CC}$, but do affect the ease of use of CC. The usefulness of $\mathrm{CC}$ is a determinant for positive intention to accept $\mathrm{CC}$, whereas the ease of use of $\mathrm{CC}$ is not. Maintainability is the strongest determinant of $\mathrm{CC}$ adoption for the full dataset, and for all individual groups, except those that use SaaS. For Hi-ITi and Lo-ITi industries, results show that managers show no differences in their perceptions of the effect of dependability attributes (availability, reliability, security) on the usefulness and the ease of CC. The absence of such a difference in managers' perception also applies to the relationship between two core variables of TAM (i.e., perceived usefulness, perceived ease of use) and behavioral intention to accept CC. For SaaS and PaaS/IaaS, managers have different perceptions of security on the usefulness of $\mathrm{CC}$, and the effect of the usefulness of $\mathrm{CC}$ on the intention to accept $\mathrm{CC}$. The findings can provide academic researchers and industry practitioners with a differentiated and in-depth perspective on the understanding and the spread of CC.
\end{abstract}

Keywords Cloud computing · Dependability $\cdot$ IT intensity $\cdot$ Service type Technology acceptance 


\section{Introduction}

Many modern organizations depend on information technology (IT) and information systems (IS); the survival of such organizations requires IT/IS that is dependable. In IT/IS literature, dependability means avoiding service failure [1]; i.e., that a system's ability to deliver multi-faceted service can justifiably be trusted (i.e., it is available, reliable, secure and maintainable) [2,3]. One of the critical concerns regarding dependability and its attributes is the difference between whether IS/ IT is dependable itself and whether users perceive that IS/IT is dependable [3, 4]. Especially, this is a primary consideration in mission-critical and large-scale distributed systems [1] like cloud computing (CC) because CC is a service-oriented technology [5].

$\mathrm{CC}$ is an innovation technology that has changed the paradigm of IT/IS [6, 7]. $\mathrm{CC}$ enables delivery of computing resources (e.g., storage, server, applications) as services [8], similar to utility services like electricity; CC provides computing resources to users (e.g., individuals, organizations) over the Internet in the form of intangible assets rather than physical assets [9]. In CC environments, products (hardware, software) are usually owned by cloud service providers (CSPs), and are transformed to services by using virtualization technology, then mainly delivered over the internet to users in the forms of software-as-a-service (SaaS), platform-as-a-service (PaaS) or infrastructure-as-a-service (IaaS) [10]. For example, a company's IS/IT department can use PaaS to build a large database on a cloud server instead of on site. This strategy means that database maintenance, security, and even safety management are transferred to CSPs. This shift raises a variety of concerns associated with dependability and its attributes of CC; users perceive $\mathrm{CC}$ to be less trustworthy than on-premise systems because the users do not have full control of computing resources and may remain locked in to a specific CSP [11-13]. These operational and technical features of CC have fueled a need for research on users' perceptions regarding CC's dependability and its attributes [14-17].

Understanding users' perceptions regarding accepting a technology is critical to the development of any technology because this understanding can further facilitate the implementation of that technology $[18,19]$. One important approach to obtain this understanding is to identify factors users' behavioral and psychological viewpoints that affect the adoption of new IS/IT [20,21]. One example is dependability and its attributes, which are the focus of this our study. Another approach is group comparison in that considers demographic (e.g., gender, culture, industry) and technological characteristics (e.g., product/service type) [22]. To the best of our knowledge, prior studies on $\mathrm{CC}$ adoption have not considered these points; our analysis of literature published from 2015 to 2021 showed a scarcity of research on the effect of dependability and its attributes on accepting $\mathrm{CC}$, and no study that performed a group comparison on the similarities and differences in $\mathrm{CC}$ adoption according to IT intensity by industry and the type of service that CC offers.

This study has three objectives: (1) to propose a research model to identify the influence of dependability and its attributes on CC adoption, (2) to empirically 
demonstrate the proposed model with data gathered from South Korea, and then (3) to compare groups that depend on high-IT-intensity industry (Hi-ITi) and low-IT-intensity industry (Lo-ITi), and SaaS and PaaS/IaaS. To reach these goals of our study, we developed and tested ten hypotheses regarding the relationships between dependability and accepting $\mathrm{CC}$; hypothesis testing using a theoretical model is widely used to explore the effect of a specific factor on accepting a technology and conduct comparison between specific groups [23, 24].

The rest of this study is structured as follows. Section 2 presents basic concepts needed to the understanding of the rest of the article. Section 3 presents related works. Section 4 proposes our research model and hypothesis. Section 5 describes our research methodology. Section 6 presents the analysis results, while Sect. 7 discusses them. Section 8 presents out contributions and implications, then Sect. 9 presents research limitation and suggests future research. Finally, Sect. 10 provides concluding remarks.

\section{Basic concepts}

\subsection{Technology acceptance theory}

Technology acceptance refers to 'the extent to which a technology is preferred for use by individuals or organizations' [20,21]. Understanding why a technology is accepted or rejected by users is as important as hardware and software engineering themselves, because this understanding can lead to successful implementation and development of the technology $[19,22]$; this consequence is especially true for service-oriented technology like CC [25]. Many researchers have developed models that use behavioral theory to understand users' acceptance or rejection of technology. These studies have largely considered two contexts [20, 26]: organizational and individual. Organizational context studies mostly used technology organization environment (TOE) theory and diffusion of innovation theory (DOI). Individual-context research has used theory of reasoned action (TRA), theory of planned behavior (TPB), technology acceptance model (TAM), extended TAM (i.e., TAM2, TAM3), unified theory of acceptance and use of technology (UTAUT), and extended UTAUT (i.e., UTAUT2). TAM has been widely used in both organizational and individual contexts due to its robustness and ease of implementation [27, 26].

\subsection{TAM}

TAM was originally proposed to explain employees' acceptance of IT/IS in work contexts [28]. The original model was redefined to consider other factors, such as removing the 'attitude' variable and introducing the 'behavioral intention' variable [29]. The final version of TAM (Fig. 1) identifies perceived usefulness and perceived ease of use as the strongest determinants that have direct effects on behavioral intention to use a technology; perceived ease of use has an effect on perceived usefulness [28-30]. Behavioral intention is the strongest determinant of actual use in IT/IS 


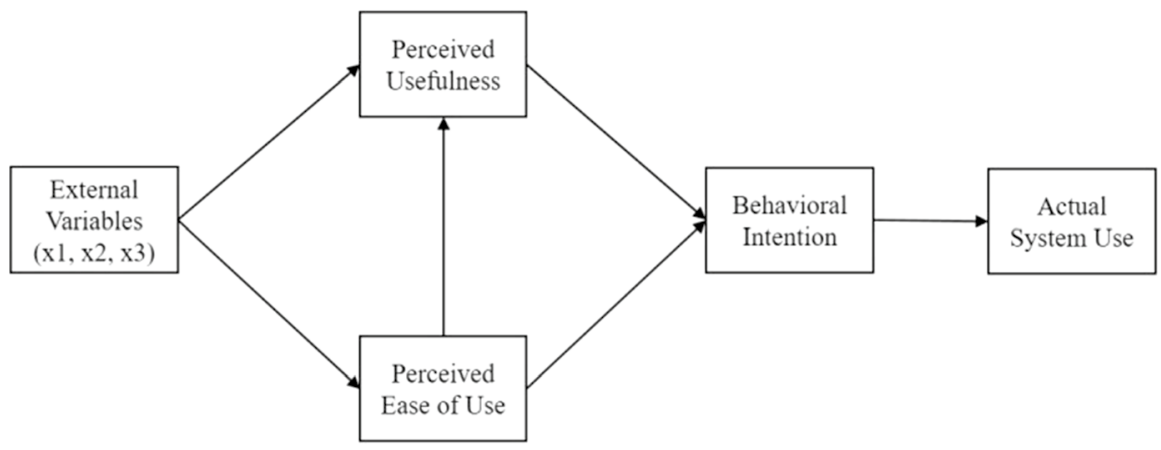

Fig. 1 The redefined technology acceptance model (Venkatesh \& Davis, 1996)

contexts [18]. TAM explains about $40-50 \%$ of the variance in behavioral intention and actual use [27]; further increase its predictive power requires that TAM should incorporate other theories or consider external variables.

\subsection{Discriminant validity and heterotrait-monotrait ratio}

Ensuring discriminant validity is one of the general requirements for model evaluation [30] such as TAM. Despite its importance, researchers have heavily relied on the Fornell and Larcker criterion that may be not suitable under certain circumstances [23]. Heterotrait-monotrait ratio (HTMT) as a new criterion was developed [30] and imposes more stringent evaluation than the Fornell and Larcker criterion [31]. HTMT criterion is an estimate of the variable correlation at the measurement item level and should be significantly $<0.9$ [24, 31, 32]. If HTMT has value $>0.90$, there is a problem with discriminant validity.

\section{Related works}

\subsection{Cloud computing}

$\mathrm{CC}$ is a distributed system that supplies computing resources such as storage to users on a pay-as-you-go method over the internet $[33,34]$. CC has several key features [10]: broad network access, on-demand service and rapid elasticity, resource polling, and measured service. The key enabler for these functions is virtualization $[35,36]$, which allows hardware, software and applications to be encapsulated into virtual machines [37] then deliver them to users. Taking storage as an example, the advantages of these features are as follows.

- Broad network access A user does not need to carry their own physical devices, nor worry about whether something (e.g., hardware/software crash, theft) can happen to them; instead of using local devices, a user only needs to upload data 
to the cloud over the internet, and then can use them on multiple devices (e.g., smartphone, laptop) at any time and place.

- On-demand self-service and rapid elasticity If necessary, a user can automatically provide, add, or expand storage resources. These capabilities reduce the user's worry about storage capacity constraints and inflexibility to emergencies such as data loss.

- Resource pooling A user does not need to install, configure, and maintain his or her own online resources (e.g., storage space). For example, security measures against malicious acts like viruses are pooled to serve multiple users, and automatic backup eliminates the need for manual data backups and the fear of backup failures.

- Measured service Users are provided with computing resources (e.g., storage space, security patches) on a pay-per-use basis, similar to traditional utility services like power and water.

CC typically offers three types of service model [10]: IaaS, PaaS, and SaaS. They are deployed to users through four delivery channels [10]: public (available to the public), private (operated solely for an organization), community (shared by several organizations), and hybrid clouds (a composition of two or more clouds). For a company that consumes all three types of cloud services in a public cloud, IaaS can provide computing disk storage in virtual environments, so an employee can access a virtual server and the data storage provided on physical infrastructure; the company's IT/IS department can use PaaS to develop and deploy its applications on the CC platform; and the company's other employees can use SaaS to access applications.

CC types are not really technologies but service models [38]. CC types can be interpreted in terms of 'who uses them' and 'why they use them'. SaaS is intended for business users (e.g., mainly employees in non-IT/IS departments), whereas PaaS is mainly for developers and deployers (e.g., mainly employees in IT/IS departments). IaaS is mainly used by IT/IS managers. SaaS focuses on providing applications to complete users' tasks. PaaS develops such solutions and deploys them for users. IaaS focuses on creating and maintaining platform and virtual resources (e.g., $\mathrm{CPU}$, storage). Therefore, SaaS is regarded as an individual-level service, whereas IaaS and PaaS are regarded as organization-level services [39]. This difference means that each service type can be perceived differently according to user context [32].

\subsection{Cloud computing dependability and its attribute}

Dependability is seen as a critical consideration in all kinds of systems [2]. Dependability means avoidance of service failures that are more severe than users can allow [40]. Especially, dependability assurance is a more important concern for a complex real-time system like CC than for a non-real-time system [41]. For example, CC can encounter a variety of runtime problems triggered by hardware and software failures including faults and errors [42]. In the CC environment, as the complexity of a cloud platform increases, various faults can cause frequent downtime accidents of virtual 
machines, and these events seriously degrade the dependability of $\mathrm{CC}$ [37]. Moreover, $\mathrm{CC}$ virtualization is generally prone to technical problems such as attacks, memory dumps, and various faults $[35,37]$. These can affect user's perceptions of CC acceptance; the current state of $\mathrm{CC}$ is not considered dependable enough for enterprise users [14, 16, 17, 27, 43].

Dependability is not a single quantity, but is composed of several attributes; suggestions include availability, reliability, safety, maintainability, performability and testability [2], reliability, availability, safety and security [44], and reliability, availability, safety, integrity, confidentiality and maintainability [3]. Among these, availability, integrity and confidentiality are elements of information security [43]. However, 'availability' stresses the absence of service failures in the context of dependability [3], so we grouped integrity and confidentiality into security, and left 'availability' as a single attribute. Safety is an extended concept of reliability; it is the same concept as reliability in that it refers to avoidance of catastrophic failures [3]. Thus, at least two overlapping properties in these classifications include availability, reliability, security, and maintainability. Enhancing these individual attributes ensures CC's dependability [45], and they can be used to measure users' perceptions of CC adoption [46].

\subsection{Technology acceptance perspective}

Our literature review of organizational-level CC adoption from 2015 to 2021 quantified the results of prior studies (Table 1). Studies for our analysis were cross-classified according to study focus and theoretical models used. Most of the studies focused on a single group to examine drivers and hindrances of CC acceptance. As far as we know, only two studies compared specific groups. One investigated the differences and similarities in IT decision makers' SaaS acceptance for core and noncore business operations [47]: perceived cost advantage affected SaaS adoption for non-core business operations but not for core business operations, whereas a gap in IT capabilities influenced SaaS adoption for core business operations but not for non-core business operations; interestingly, perceived service quality had a positive effect, and management attitude had a negative effect on SaaS acceptance for both types of business operations. The other considered adopters and non-adopter firms [48]: for both types, perceived ubiquity and perceived benefits were determinant for positive CC adoption, whereas perceived risks was a determinant for negative CC adoption; perceived costs influenced $\mathrm{CC}$ adoption for adopter firms but not for nonadopter firms.

However, research has little considered how CC adoption differs among industry and service type; i.e., researchers have overlooked the influence of the variation in IT intensity among industries (e.g., high vs. low) and among service types (e.g., SaaS vs. PaaS vs. IaaS). Prior CC studies have emphasized the necessity to consider those points, but have not led to empirical validation: two have suggested that different industries besides high-tech industry may adopt $\mathrm{CC}$ at different rate $[50,63]$; and three have suggested that different cloud types may induce different adoption behaviors [64-66]. 


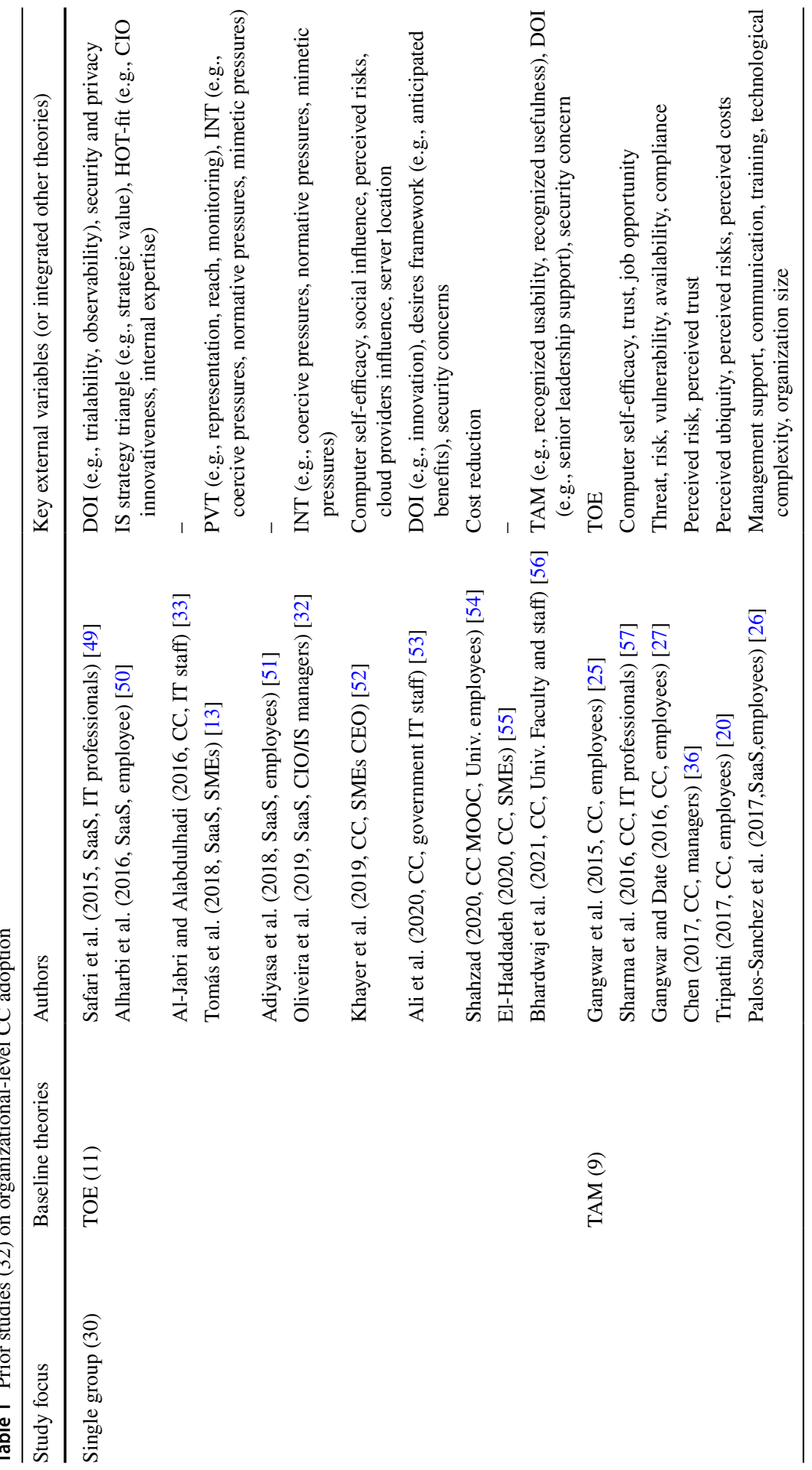




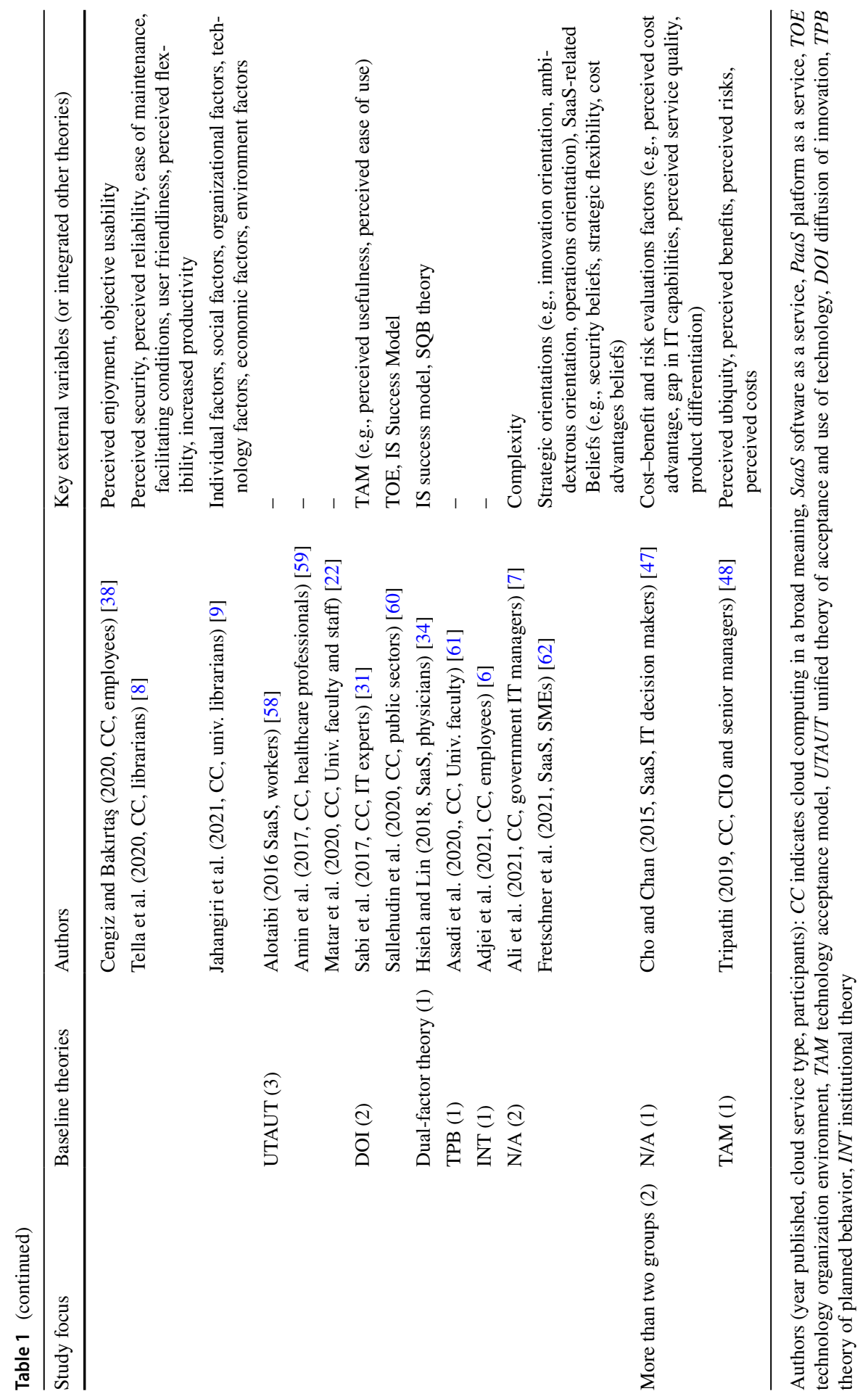


In contrast, other research realms have showed that IT intensity and service type can affect technology acceptance: each industry may have a different behavior towards adopting a technology $[67,68]$; behaviors toward technology adoption may depend on service type [28, 69]. Regarding IT intensity by industry type, executives' perceptions of adopting anti-malware differ among industries [70]. Also, an industry that sells information-intensive services may be more likely to adopt new technology than are industries that do not sell such services [71]. Regarding service types, patterns of adoption of banking channels (e.g., internet banking, phone banking) depend on service type [72]. Especially, utilitarian service type can significantly affect users' adoption of mobile data services [73].

Regarding the theories used, TOE and its derivatives were the most frequently employed (11 papers), followed by TAM and its derivatives (10), UTAUT and its derivatives (3), and DOI and its derivatives (2). Interestingly, even research on organizational $\mathrm{CC}$ adoption used individual-level theories (e.g., TAM, UTAUT) to study the perceptions of technology adoption at specific user levels (e.g., IT/IS managers) in organizations because of the ease of combining with other theories or extending the model using external variables. Use of these theoretical models helped to identify drivers and inhibitors of CC acceptance that fit the contexts of their studies.

To the best of our knowledge, prior studies have not considered the influence of dependability on $\mathrm{CC}$ acceptance in an organizational context from both the technology acceptance perspective and the holistic perspective on the concept of dependability. Instead, nine studies 'chose' one or two more of dependability attributes or similar concepts, and then incorporated them with the core constructs of their original models for their research goals: availability [27], perceived ubiquity [20, 48], reliability [8], security [8, 49, 53, 56], perceived risk [20, 27, 36, 48, 52], ease of maintenance [8]. Moreover, most of them focused on the direct relationships between the dependent variable of baseline model (i.e., behavioral intention in TAM) and external variables, not on the relationships between the core constructs of the baseline models (i.e., perceived usefulness, perceived ease of use in TAM) and external variables.

$\mathrm{CC}$ in a broad sense was the most frequently targeted technology (22 papers), followed by SaaS (10). $21(65.6 \%)$ of the studies targeted general employees, followed by IS/IT professionals (6) [7, 31, 33, 49, 53, 57], decision makers (4) [32, 47, 48, 52], and managers (1) [36]. Interestingly, six studies targeted studies university faculty/staff $[9,22,54,61]$ and academic libraries [8, 9], four studies small and medium enterprises [13, 48, 52, 55, 62], and three studies public sectors $[7,53,60]$.

This literature review found no empirical study that: (1) explored the effect of dependability and its individual attributes on $\mathrm{CC}$ adoption with a holistic point of view, or (2) examined the similarities and differences in CC acceptance in terms of industry and service type. This study fills these research gaps: (1) This study introduced dependability as a multi-faceted notion to CC acceptance study. This is the first empirical research that integrates dependability attributes (availability, reliability, security, maintainability) with technology acceptance theory. (2) This study identified the influence of dependability attributes on accepting $\mathrm{CC}$ at the 


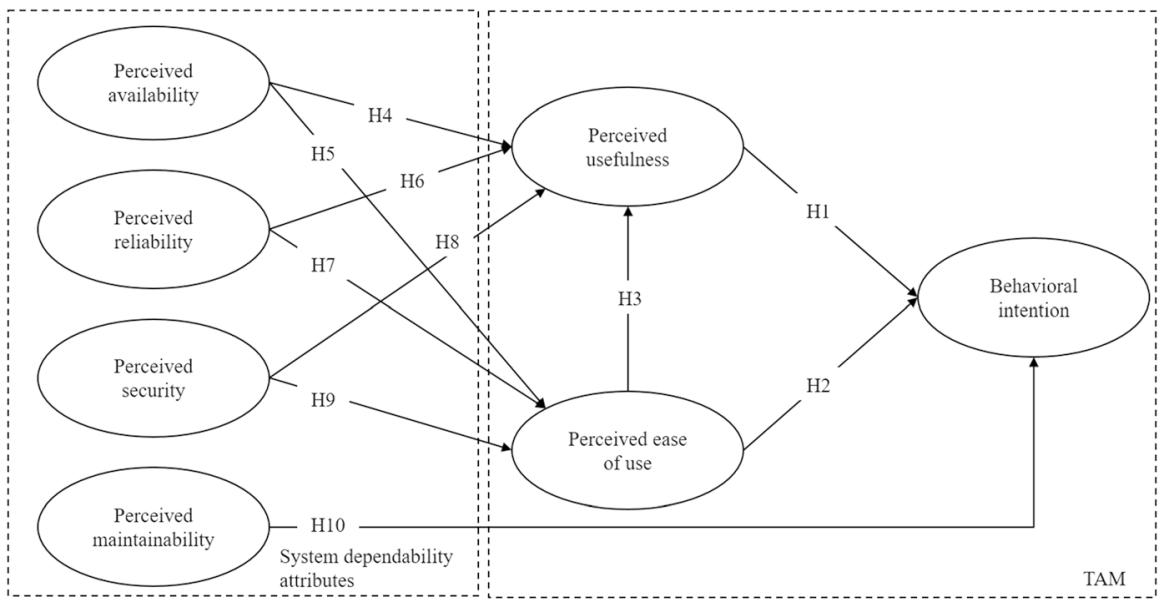

Fig. 2 Research model and hypotheses

organizational context, and showed the similarities and differences in CC acceptance between specific groups (Hi-ITi vs. Lo-ITi, SaaS vs. PaaS/IaaS).

\section{Research model and hypotheses}

\subsection{Research model}

This study proposes a reflective model that integrates four dependability attributes with TAM (Fig. 2): TAM is used as a baseline model because of its robustness and simplicity. This study adopted CC as a target technology because CC is a good representation of system dependability and its attributes. This model consists of four exogenous constructs (availability, reliability, security, maintainability), one final endogenous construct (behavioral intention), and two explanatory constructs (perceived usefulness, perceived ease of use) that simultaneously serve as exogenous and endogenous variables. Actual use was excluded because we accept that behavioral intention is the strongest determinant of actual use in IT/IS contexts [18, 29].

\subsection{Hypothesis development}

This study proposes ten hypotheses that connect measures of CC's dependability to behavioral intention to use, either directly, or indirectly via perceived usefulness and perceived ease of use.

Perceived usefulness (PUF) refers to the degree to which users believe that using a technology would enhance his or her job performance [28, 29]. It is similar to performance expectancy in UTAUT/UTAUT2 and relative advantage in TOE/DOI 
[18]. In the context of CC, perceived usefulness concerns improvements in task productivity obtained from using CC as a result of its technical features such as broad network access. Previous CC adoption studies have showed that perceived usefulness has a positive effect on behavioral intention to use of CC [20, 22, 25-27, 36, 38, 49, 51, 52, 54, 56-59]. Consequently, if managers perceive CC to be useful, behavioral intention to use the system would likely increase. Thus, we propose:

$\mathrm{H} 1$ Perceived usefulness of $\mathrm{CC}$ increases manager's behavioral intention to use $\mathrm{CC}$.

Perceived ease of use (PEU) measures the extent to which users believe that a new technology can be used without effort [28, 29]. This concept captures others such as effort expectancy in UTAUT/UTAUT2 and complexity/ease of use in TOE/ DOI [18]. In the context of CC, this measure quantifies the simplicity of using a CC that operated over on the internet. The easiness of $\mathrm{CC}$ has a direct effect on the usefulness of $\mathrm{CC}$ because an easy technology reduces the effort required to accomplish tasks. Prior studies have shown that perceived ease of use is a critical determinant of behavioral intention to use CC [25-27, 36, 38, 49, 57-59] and is a causal antecedent of perceived usefulness [20, 25-27, 36]. Consequently, if managers believe that they need to exert little effort to use $\mathrm{CC}$, then behavioral intention to use $\mathrm{CC}$ and perceived usefulness would likely increase. Thus, we propose:

H2 Perceived ease of use of CC increases manager's behavioral intention to use CC.

H3 Perceived ease of use of CC increases manager's perceived usefulness of CC.

Availability refers to the readiness for correct service in dependable systems' view $[2,3]$; it is perceived by a user as the degree to which he or she believes that a new technology provides relevant service anytime and anywhere [27, 74]. Perceived availability is similar to the concept of perceived ubiquity in the IT/IS area [74]. Some previous studies of $\mathrm{CC}$ adoption have indicated that perceived availability (or similar concepts) positively affect the usefulness [27, 74] and the ease of CC [27]. Consequently, in the CC context, the availability of CC anytime and anywhere through the internet and various devices is likely to make managers feel that $\mathrm{CC}$ is useful and easy to use. Thus, we propose:

H4 Perceived availability of CC increases manager's perceived usefulness of CC.

H5 Perceived availability of CC increases manager's perceived ease of use of CC.

Reliability refers to the continuity of correct service in dependable systems' view $[2,3]$; it is perceived by a user as the degree to which he or she believes that a new technology responds consistently and functions accurately (e.g., guaranteed service 24/7) [75, 76]. Perceived reliability is about reliable service delivery of CC and fault tolerance against catastrophic failures [76]. To the best of our knowledge, few studies have examined both the effects of reliability on usefulness and ease of use of 
$\mathrm{CC}$ in an organizational context; only one study showed that reliability is positively related to the ease of CC when SMEs adopt CC [76]. Instead, another study that focused on individual-level $\mathrm{CC}$ adoption showed that perceived reliability works as an antecedent of the usefulness and the ease of CC in students' CC adoption of community colleges [77]. Consequently, in the CC context, increase in managers' perceptions that $\mathrm{CC}$ works well under any situations will lead to an increase in the likelihood that they perceive $\mathrm{CC}$ to be useful and easy to use. Thus, we propose:

H6 Perceived reliability of CC increases manager's perceived usefulness of CC.

$\mathrm{H} 7$ Perceived reliability of CC increases manager's perceived ease of use of CC.

Security refers to the prevention of unauthorized access [2, 3], and is perceived by a user as the degree to which he or she believes that the $\mathrm{CC}$ provides protection against disclosure, modification, destruction, fraud, and abuse [78, 79]. Perceived security concerns are seen as a key obstacle to new IT/IS adoption including CC [13, 74]. Similar to the case of reliability, few studies have explored the influence of security on the usefulness and the ease of $\mathrm{CC}$, except for one study [76], which validated the positive relationship between reliability and the ease of use. In other IT/IS areas, perceived security has a positive effect on perceived usefulness [80] and perceived ease of use [80, 81]. Consequently, in the $\mathrm{CC}$ context, as managers' perceptions of $\mathrm{CC}$ as secure increase, their perceptions of the usefulness and the ease of $\mathrm{CC}$ will also increase. Thus, we propose:

H8 Perceived security of CC increases manager's perceived usefulness of CC.

H9 Perceived security of CC increases manager's perceived ease of use of CC.

Maintainability refers to the ability to undergo modifications and repairs [2, $3]$; it is perceived by a user as the degree to which he or she believes that technology providers perform appropriate maintenance in hardware and software aspects [82]. CC helps users to eliminate the burden of maintaining hardware and software in on-premise systems because CSPs take the place of maintenance; if managers perceive that $\mathrm{CC}$ is accompanied by good maintenance, they will be likely to adopt CC. Contrarily, if the user's perception is that the maintainability is not good, the consequence is a decrease in the likelihood that they accept the technology. Although the inherent nature of $\mathrm{CC}$ leads to an in- creasing interest in maintainability, little empirical study is available for the effect of maintainability on CC adoption. Instead, ease of maintenance was found to be a more important consideration than other factors (e.g., reliability) in an interview of IT professionals concerning CC adoption [65] and in an analytic hierarchy process of drivers and inhibitors of SaaS adoption [82]. Thus, we propose: 
$\mathrm{H} 10$ Perceived maintainability of CC increases manager's behavioral intent to use CC.

\section{Methods}

\subsection{Measurement development}

This research used a survey method. A structured questionnaire was developed to conduct a survey to collect data. Most measurements scales in the questionnaire have been validated in previous studies, and maintainability scales were developed due to the lack of prior studies related to the maintainability attribute ("Appendix 1"). Twenty- seven items regarding all the constructs in our research model were designed for the questionnaire. It was developed in English, then translated to Korean by bilingual researchers who used the back-translation technique. Scales were reviewed by $10 \mathrm{CC}$ experts, then modified to fit our study. Respondents were required to evaluate their perceptions of $\mathrm{CC}$ by scoring a seven-point Likert scale (from $1=$ strongly disagree to 7 = strongly agree).

\subsection{Sample}

This study targeted business managers who work in various departments within an organization in various industries, and who are aware of CC. However, the correct size of target population was not available in South Korea, so a professional online survey firm (i.e., Entrust Survey) was used to collect appropriate participants (i.e., business managers), who were recruited according to the well-organized panel-filtering policy of the survey firm. A pilot study with twenty university students was conducted first to test the wording and clarity of the questionnaire, and time required to complete it. The questionnaire was revised in response to the students' feedback. Then, the final questionnaire was given to and managed by the survey firm. Two hundred and thirty surveys were collected online during a span of 4 months (December 2019-March 2020) from the registrants pool of the survey firm. None of the scores was an obvious outlier, so all surveys were used for our analysis. All processes of this survey were approved by the academic ethics committee.

\subsection{Data analysis}

Data were first analyzed using SPSS 23.0 statistical software, to examine demographic characteristics of sample respondents ("Appendix 2"). Most (87.0\%) of respondents had more than 6 years of experience in job positions as first and middleline managers $(96.1 \%)$; they conducted main tasks in mainly management $(46.1 \%)$, R\&D/IT (33.9\%) and production (10.9\%). The industries in which the participants are employed were manufacturing $(30.0 \%)$, IT $(19.6 \%)$, service $(12.6 \%)$, government/public area (11.7\%), engineering (7.4\%), wholesale/retails $(7.45 \%)$, energy/ 
chemicals/utilities (4.3\%), telecommunications (3.9\%), and finance (3.0\%). Most $(73.5 \%)$ of the organizations ran domestic and local businesses. The number of employees were mainly below $300(50.4 \%)$ or 300-1000 (37.8\%). Annual sales were mostly (89.6\%) KRW 1 billion-5 trillion.

One of our research goals is to explore the similarities and differences between groups (Hi-ITi vs. Lo-ITi; SaaS vs. PaaS/IaaS). To conduct a multi-group analysis, we first reclassified industry type into Hi-ITi (117; e.g., financing, IT, telecommunication) and Lo-ITi (113; e.g., manufacturing, energy/chemicals/utilities, engineering, wholesale/retails) [70, 83-85]. In South Korea, the government/public sector [86] and service sector [87] are Hi-ITi. This study combined PaaS and IaaS into one group (PaaS/IaaS) because they mainly target organizational-level services; thus, service type is divided into SaaS (88) and PaaS/IaaS (82) for analysis.

Analysis then applied structural equation modeling (SEM) to validate the proposed model, using the collected data: i.e., assessment of measurement model and the structural model. SEM is a multivariate statistical method that allows analysis of casualty among latent variables [23]. SEM can use two techniques [24]: covariancebased SEM (e.g., analysis of moment structures) and variance-based SEM (e.g., partial least squares: PLS). The former is for testing theory, confirming theory or comparing alternative theories, whereas the latter is for predicting target variables or identifying key influencing variables [23] as in our study. PLS was used to conduct the test of measurement and structural model by using SmartPLS3.0, which is latent-variable modeling-software (SmartPLS GmbH) that uses a graphical user interface. We chose PLS-SEM because [24] it evaluates both the measurement and structural model at the same time, and can work with small sample size.

PLS-SEM minimum sample size should be ten times the largest number of structural paths directed at a particular latent variable in the structural model [23]. The highest number of relationship towards a latent construct in this research is that towards perceived usefulness, consisting of four relationships. Thus, the required minimum sample size is 40 respondents; our sample size of 230 fulfills this requirement.

\section{Results}

Analysis results are present in three-steps: measurement model analysis, structural model analysis, and multi- group analysis.

\subsection{Measurement model analysis}

A measurement invariance test is an important step to be performed when conducting a group comparison [24, 88]. This test checks whether measurement operations differ across comparison groups: in our study, Hi-ITi versus Lo-ITi, and SaaS versus PaaS/IaaS. Overall, the results indicated good measurement invariance (“Appendix 3"). However, the initial evaluation did not report full measurement invariance. Investigation of outer loadings-differences between comparison groups 
demonstrated that two indicators yielded different meanings across them: PUF1 of perceived usefulness (Hi-ITi vs. Lo-ITi) with $p=0.027$, and PUF2 of perceived usefulness (SaaS vs. PaaS/IaaS) with $p=0.025$, so these indicators were deleted from the original model. Finally, none of the measurement items were variant across the groups, with $0.001 \leq$ outer loadings-diff (Hi-ITi vs. Lo-ITi) $\leq 0.104$, and with $0.002 \leq$ outer loadings-diff $(\mathrm{SaaS}-\mathrm{PaaS} / \mathrm{IaaS}) \leq 0.080$; i.e., comparison groups do not differ significantly in their measurement invariance.

PLS-SEM algorithm was run to evaluate the reliability, the convergent validity, and the discriminant validity of the scales in the outer model. Reliability was tested using composite reliability (CR). Convergent validity was assessed using factor loading and average variance extracted (AVE). Finally, the Fornel-Lacker criterion and the HTMT criterion were used to assess discriminant validity.

All indices were within the recommended values in all assessment criteria (Table 2). All CR values exceeded the minimum threshold of 0.70 [23]; this result internal consistency among the constructs. All indicators had factors loading $>0.70$, except one $(\mathrm{PRE}=0.682)$, and AVEs were above the minimum threshold of 0.50 , this result indicates acceptable convergent validity. The square root of AVE for all constructs in each group was much larger than its correlations with other constructs, and all groups passed the HTMT.90 criterion [23, 24] (Tables 3, 4, 5, 6, and 7); these results confirm discriminant validity. The most important information on each table are highlighted in bold

To assess multicollinearity among latent variables, the variance inflation factor (VIF) method was used ("Appendix 4"). All VIF values were within the maximum threshold of 5.0 [24], with $1.440 \leq \mathrm{VIF}$ of full data set $\leq 2.801,1.337 \leq \mathrm{VIF}$ of $\mathrm{Hi}-\mathrm{ITi} \leq 3.069,1.548 \leq \mathrm{VIF}$ of $\mathrm{Lo}-\mathrm{ITi} \leq 2.809$, $1.703 \leq \mathrm{VIF}$ of $\mathrm{SaaS} \leq 3.126$, and $1.507 \leq \mathrm{VIF}$ of $\mathrm{PaaS} / \mathrm{IaaS} \leq 2.759$. Thus, this model has no multicollinearity problem.

\subsection{Structural model analysis}

This study included a bootstrapping and blindfolding process to get the structural estimates: coefficient of determination $\left(R^{2}\right)$, predictive relevance $\left(Q^{2}\right)$, effect size $\left(f^{2}\right)$, and path coefficients $(\beta)$ (Tables 8, 9 and 10). All groups had $\mathrm{R}^{2}>0.5$, which suggests that the exogenous constructs explained more than $50 \%$ of the variance in behavioral intent. All groups had $Q^{2}>0$, which indicates that the exogenous constructs have sufficient predictive relevance over their endogenous construct. $f^{2}$ shows the relative effect of an exogenous variable on an endogenous variable [24]; $f^{2}=0.02,0.15$, and 0.35 indicate a weak, moderate, strong effect, respectively. Perceived usefulness (PUF) had the highest $f^{2}=0.586$ on behavioral intention (BI) in SaaS. The effects of perceived availability (PAV), perceived reliability (PRE) and perceived security (PSE) on PUF in all groups were fairly weak or weak, whereas their effects on perceived ease of use (PEU) were moderate or much greater than their effects on PUF. Perceived maintainability (PMA) had large effect size on BI, and PEU had large effect size on PUF in all groups except SaaS, but the effect size 


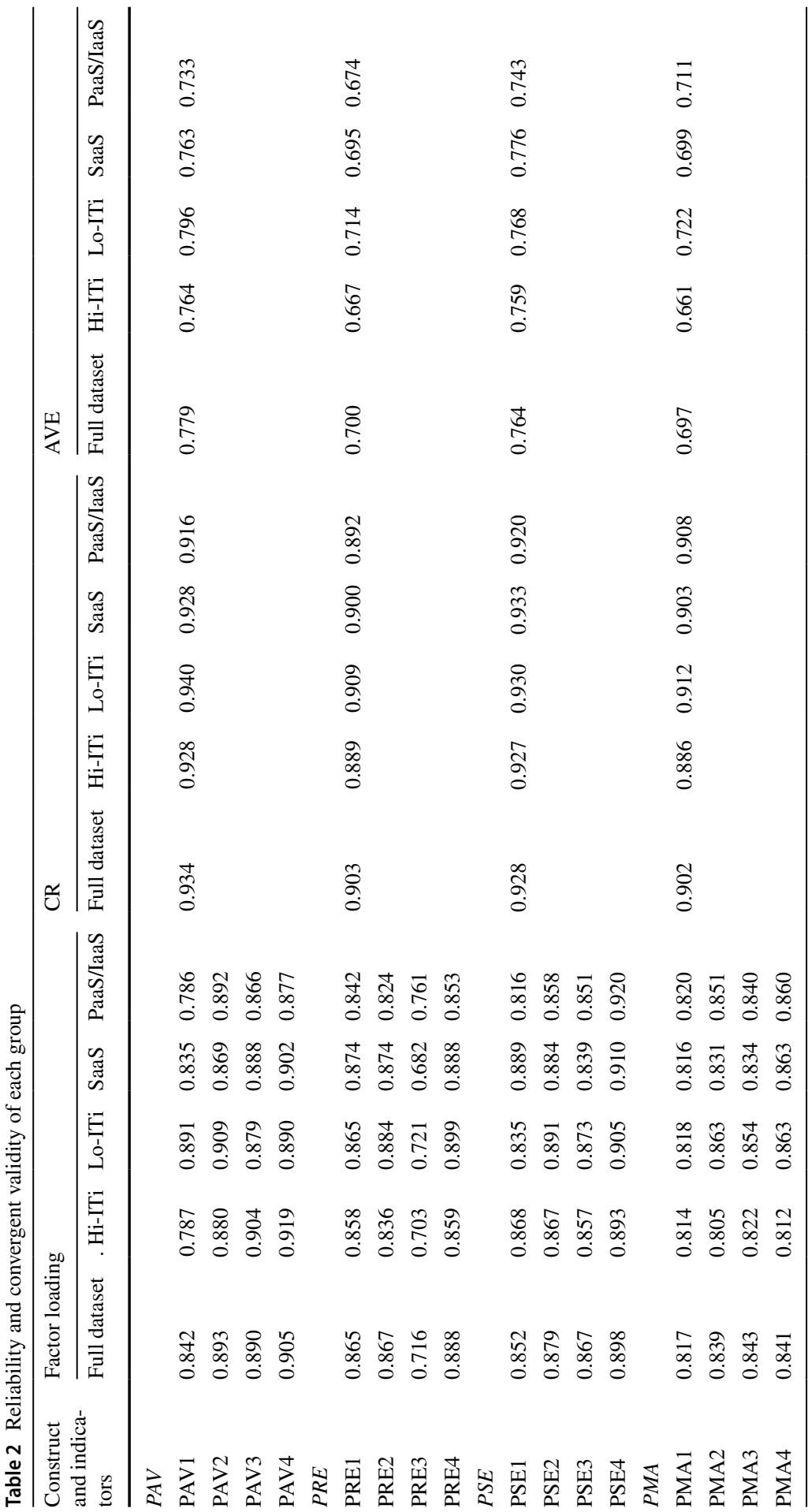




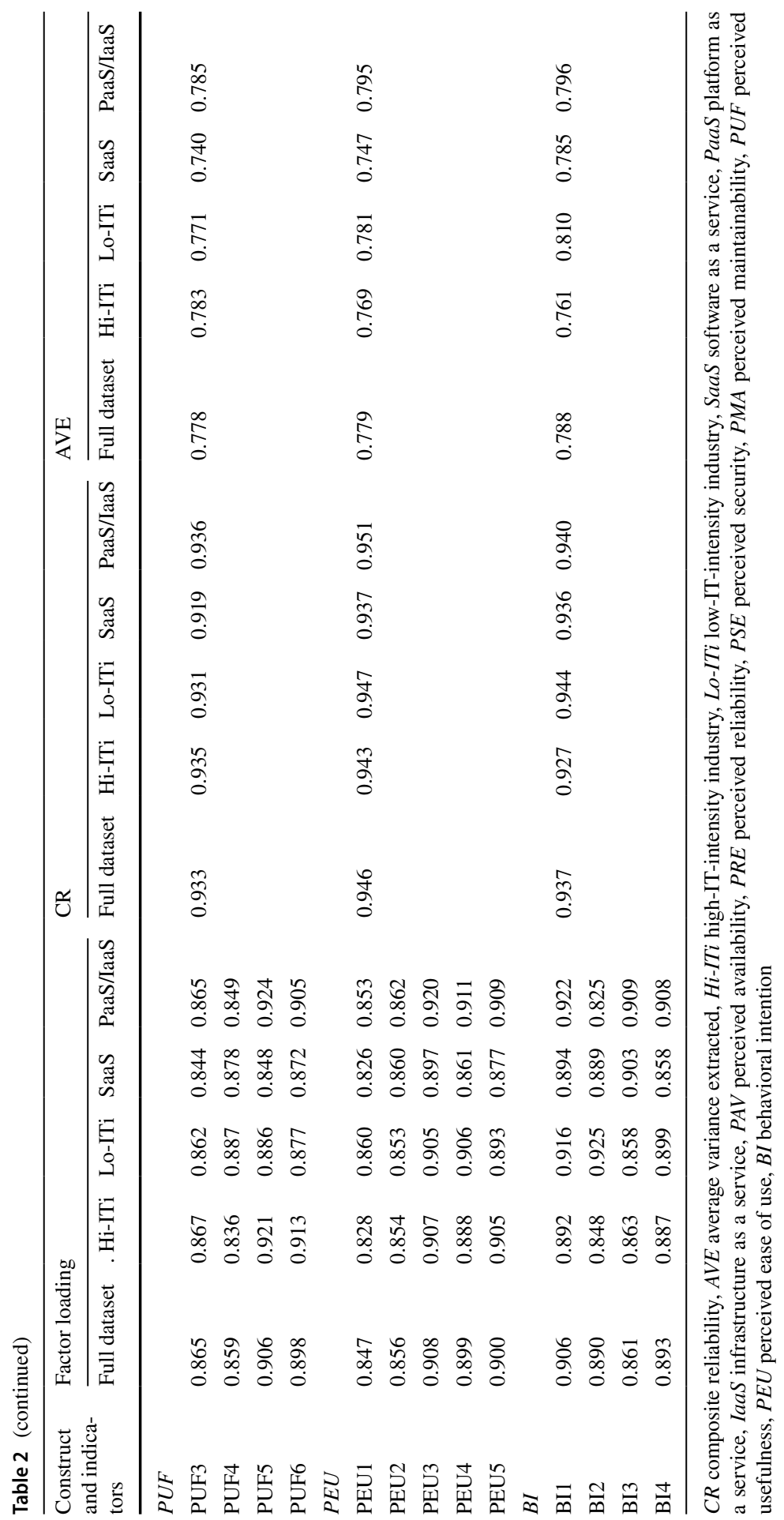




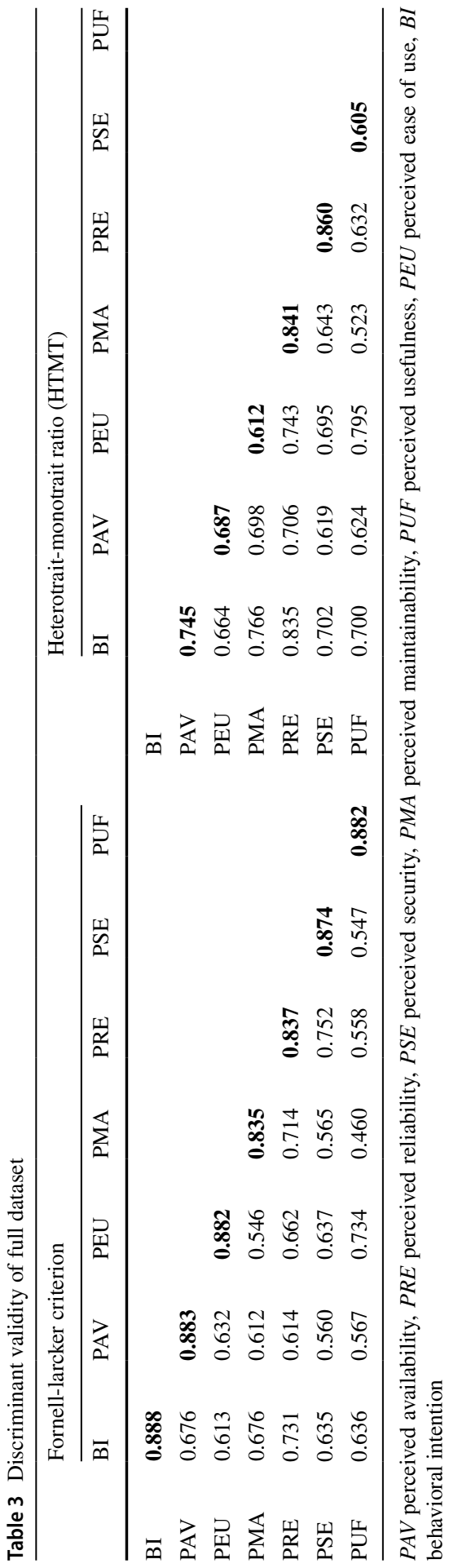




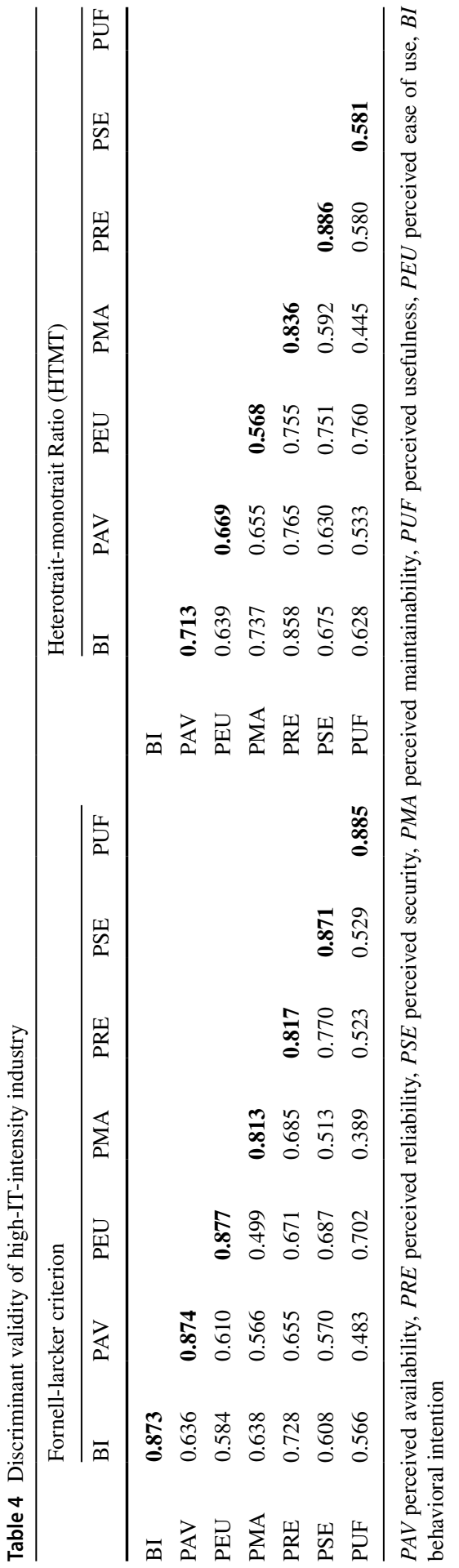




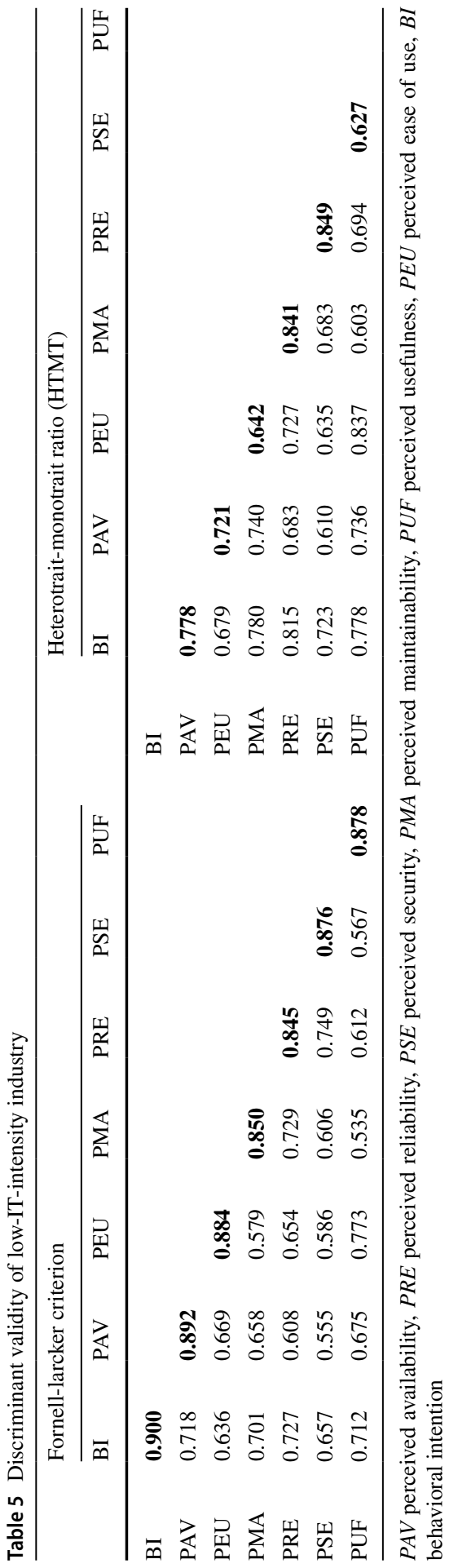




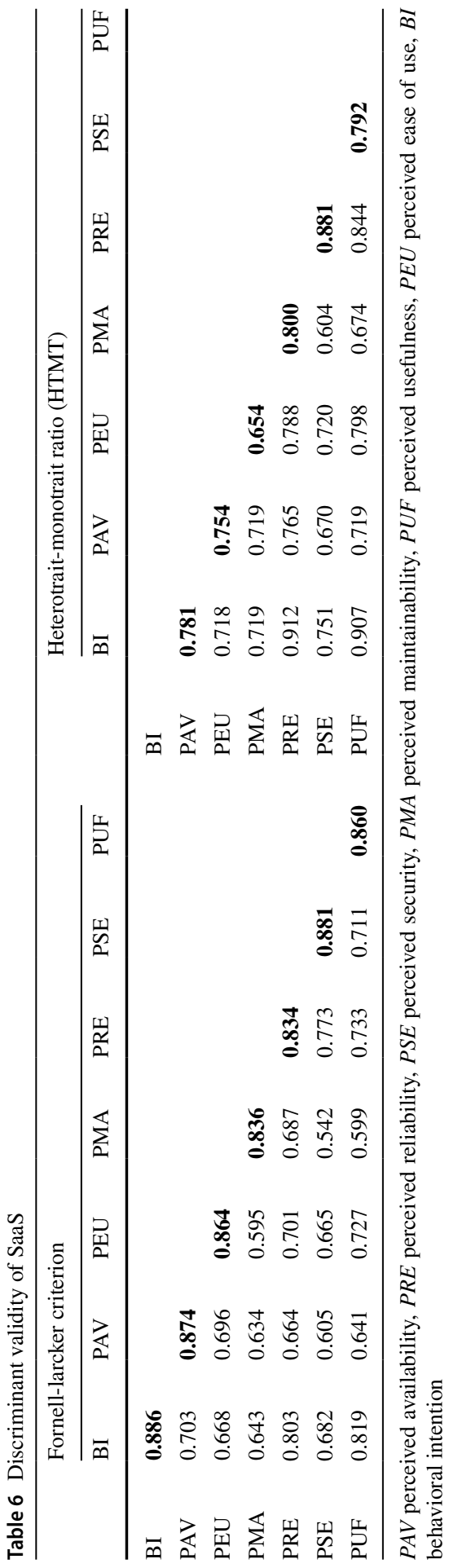




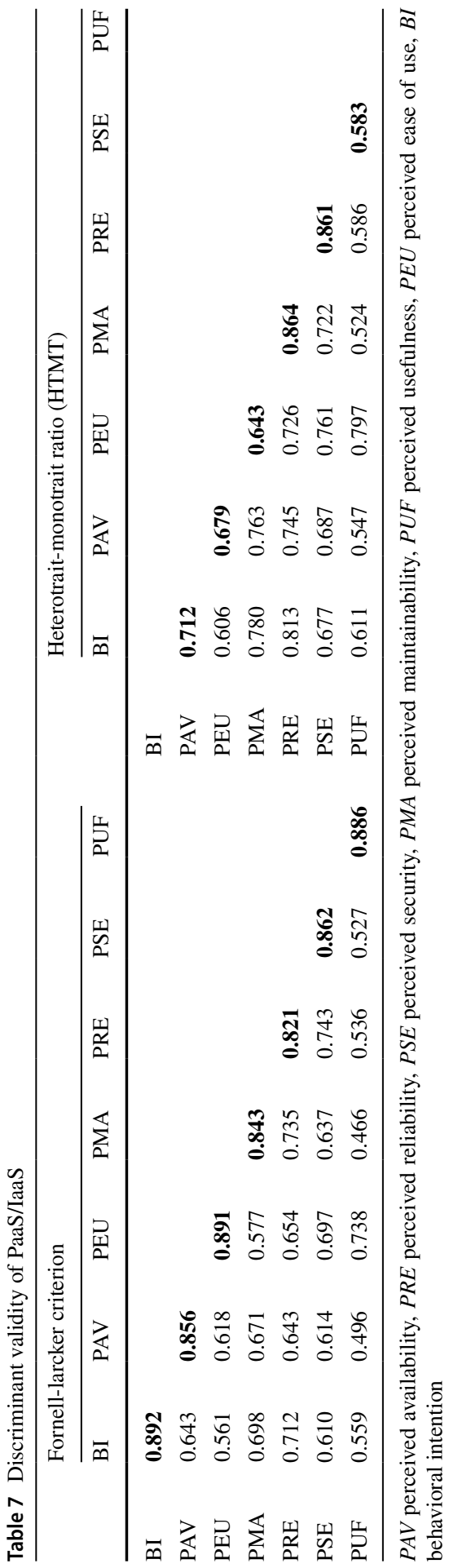


Table $8 R^{2}, Q^{2}$ and $f^{2}$ for full dataset

\begin{tabular}{|c|c|c|c|c|c|}
\hline \multirow[t]{3}{*}{ Construct } & \multicolumn{5}{|c|}{ Full dataset } \\
\hline & \multirow[t]{2}{*}{$\overline{R^{2}}$} & \multirow[t]{2}{*}{$Q^{2}$} & \multicolumn{3}{|l|}{$f^{2}$} \\
\hline & & & BI & PEU & PUF \\
\hline BI & 0.590 & 0.436 & & & \\
\hline PAV & & & & 0.138 & 0.024 \\
\hline PEU & 0.539 & 0.391 & 0.012 & & 0.340 \\
\hline PMA & & & 0.358 & & \\
\hline PRE & & & & 0.064 & 0.001 \\
\hline PSE & & & & 0.056 & 0.005 \\
\hline PUF & 0.554 & 0.405 & 0.134 & & \\
\hline
\end{tabular}

$P A V$ perceived availability, $P R E$ perceived reliability, $P S E$ perceived security, $P M A$ perceived maintainability, $P U F$ perceived usefulness, $P E U$ perceived ease of use, $B I$ behavioral intention

Table $9 R^{2}, Q^{2}$ and $f^{2}$ for IT intensity

\begin{tabular}{|c|c|c|c|c|c|c|c|c|c|c|}
\hline \multirow[t]{3}{*}{ Construct } & \multicolumn{5}{|l|}{ Hi-ITi } & \multicolumn{5}{|c|}{ Lo-ITi } \\
\hline & \multirow[t]{2}{*}{$R^{2}$} & \multirow[t]{2}{*}{$Q^{2}$} & \multicolumn{3}{|l|}{$f^{2}$} & \multirow[t]{2}{*}{$R^{2}$} & \multirow[t]{2}{*}{$Q^{2}$} & \multicolumn{3}{|l|}{$f^{2}$} \\
\hline & & & BI & PEU & PUF & & & BI & PEU & PUF \\
\hline BI & 0.527 & 0.377 & & & & 0.641 & 0.479 & & & \\
\hline PAV & & & & 0.082 & 0.004 & & & & 0.229 & 0.083 \\
\hline PEU & 0.546 & 0.392 & 0.028 & & 0.324 & 0.539 & 0.395 & 0.001 & & 0.351 \\
\hline PMA & & & 0.326 & & & & & 0.359 & & \\
\hline PRE & & & & 0.035 & 0.001 & & & & 0.082 & 0.004 \\
\hline PSE & & & & 0.128 & 0.002 & & & & 0.015 & 0.007 \\
\hline PUF & 0.483 & 0.351 & 0.082 & & & 0.638 & 0.461 & 0.229 & & \\
\hline
\end{tabular}

$H i-I T i$ high-IT-intensity industry, Lo-ITi low-IT-intensity industry, $P A V$ perceived availability, $P R E$ perceived reliability, $P S E$ perceived security, $P M A$ perceived maintainability, $P U F$ perceived usefulness, $P E U$ perceived ease of use, $B I$ behavioral intention

did not differ significantly between comparison groups, except ISaaS-PaaS/IaaS| (i.e., PUF $\rightarrow$ BI) (Table 11).

This study investigated the hypothesized relationships in each group including the full dataset (Figs. 3 and 4, Table 12). Overall, assessing from the path coefficients alone, the TAM-related hypothesis test results were the same in comparison groups, but the dependability-related hypothesis test reported different results among them. This distinction suggests that manager's perceptions of adopting CC may differ between Hi-ITi and Lo-ITi, and between SaaS and PaaS/IaaS.

Perceived usefulness significantly affected behavioral intention to adopt $\mathrm{CC}$ for the full data set $(\beta=0.345, p<0.001)$, Hi-ITi $(\beta=0.273, p<0.01)$, Lo-ITi $(\beta=0.452$, $p<0.001)$, SaaS $(\beta=0.630, p<0.001)$, and PaaS/Paas $(\beta=0.270, p<0.05)$; thus, H1 is supported for all groups. Perceived ease of use was not significant for any group; 
Table $10 R^{2}, Q^{2}$ and $f^{2}$ for service type

\begin{tabular}{|c|c|c|c|c|c|c|c|c|c|c|}
\hline \multirow[t]{3}{*}{ Construct } & \multicolumn{5}{|l|}{ SaaS } & \multicolumn{5}{|c|}{ PaaS/IaaS } \\
\hline & \multirow[t]{2}{*}{$R^{2}$} & \multirow[t]{2}{*}{$Q^{2}$} & \multicolumn{3}{|l|}{$f^{2}$} & \multirow[t]{2}{*}{$\overline{R^{2}}$} & \multirow[t]{2}{*}{$Q^{2}$} & \multicolumn{3}{|l|}{$f^{2}$} \\
\hline & & & BI & PEU & PUF & & & BI & PEU & PUF \\
\hline BI & 0.699 & 0.513 & & & & 0.541 & 0.395 & & & \\
\hline PAV & & & & 0.192 & 0.015 & & & & 0.073 & 0.002 \\
\hline PEU & 0.591 & 0.406 & 0.009 & & 0.112 & 0.543 & 0.405 & 0.002 & & 0.454 \\
\hline PMA & & & 0.097 & & & & & 0.446 & & \\
\hline PRE & & & & 0.068 & 0.061 & & & & 0.036 & 0.008 \\
\hline PSE & & & & 0.048 & 0.061 & & & & 0.150 & 0.002 \\
\hline PUF & 0.638 & 0.440 & 0.586 & & & 0.528 & 0.381 & 0.075 & & \\
\hline
\end{tabular}

SaaS software as a service, PaaS platform as a service, IaaS infrastructure as a service, $P A V$ perceived availability, $P R E$ perceived reliability, $P S E$ perceived security, $P M A$ perceived maintainability, $P U F$ perceived usefulness, $P E U$ perceived ease of use, $B I$ behavioral intention

Table 11 Results of effect size $\left(f^{2}\right)$ differences

\begin{tabular}{|c|c|c|c|c|}
\hline \multirow[t]{2}{*}{ Construct } & \multicolumn{2}{|c|}{ Hi-ITi versus Lo-ITi } & \multicolumn{2}{|c|}{$\begin{array}{l}\text { SaaS versus PaaS/ } \\
\text { IaaS }\end{array}$} \\
\hline & $f^{2} \operatorname{diff}$ & $p$-value & $f^{2}$ diff & $p$-value \\
\hline $\mathrm{PAV} \rightarrow \mathrm{PUF}$ & 0.079 & 0.726 & 0.014 & 0.351 \\
\hline $\mathrm{PAV} \rightarrow \mathrm{PEU}$ & 0.147 & 0.831 & 0.118 & 0.211 \\
\hline $\mathrm{PRE} \rightarrow \mathrm{PUF}$ & 0.003 & 0.435 & 0.053 & 0.305 \\
\hline $\mathrm{PRE} \rightarrow \mathrm{PEU}$ & 0.048 & 0.729 & 0.032 & 0.335 \\
\hline $\mathrm{PSE} \rightarrow \mathrm{PUF}$ & 0.006 & 0.680 & 0.059 & 0.115 \\
\hline $\mathrm{PSE} \rightarrow \mathrm{PEU}$ & 0.113 & 0.109 & 0.102 & 0.766 \\
\hline $\mathrm{PMA} \rightarrow \mathrm{BI}$ & 0.033 & 0.541 & 0.349 & 0.858 \\
\hline $\mathrm{PUF} \rightarrow \mathrm{BI}$ & 0.147 & 0.832 & 0.512 & 0.013 \\
\hline $\mathrm{PEU} \rightarrow \mathrm{BI}$ & 0.026 & 0.478 & 0.007 & 0.308 \\
\hline $\mathrm{PEU} \rightarrow \mathrm{PUF}$ & 0.026 & 0.561 & 0.343 & 0.809 \\
\hline
\end{tabular}

$H i$-ITi high-IT-intensity industry, Lo-ITi low-IT-intensity industry, SaaS software as a service, PaaS platform as a service, IaaS infrastructure as a service, $P A V$ perceived availability, $P R E$ perceived reliability, $P S E$ perceived security, $P M A$ perceived maintainability, $P U F$ perceived usefulness, $P E U$ perceived ease of use, $B I$ behavioral intention

hence, $\mathrm{H} 2$ is rejected. Perceived usefulness was predicted by perceived ease of use in all groups (full data set: $\beta=0.572, p<0.001$; Hi-ITi: $\beta=0.605, p<0.001$; LoITi: $\beta=0.523, p<0.001$; SaaS: $\beta=0.313, p<0.01$; PaaS/IaaS: $\beta=0.681, p<0.001$ ); hence, $\mathrm{H} 3$ is supported.

Perceived availability (PAV), perceived reliability (PRE), and perceived security (PSE) had no significant effect on perceived usefulness for any group, except SaaS $(\beta=0.238, p<0.05)$; hence, $\mathrm{H} 4$ and $\mathrm{H} 6$ were rejected for all groups. H8 was accepted for SaaS, but rejected for other groups. Perceived maintainability 


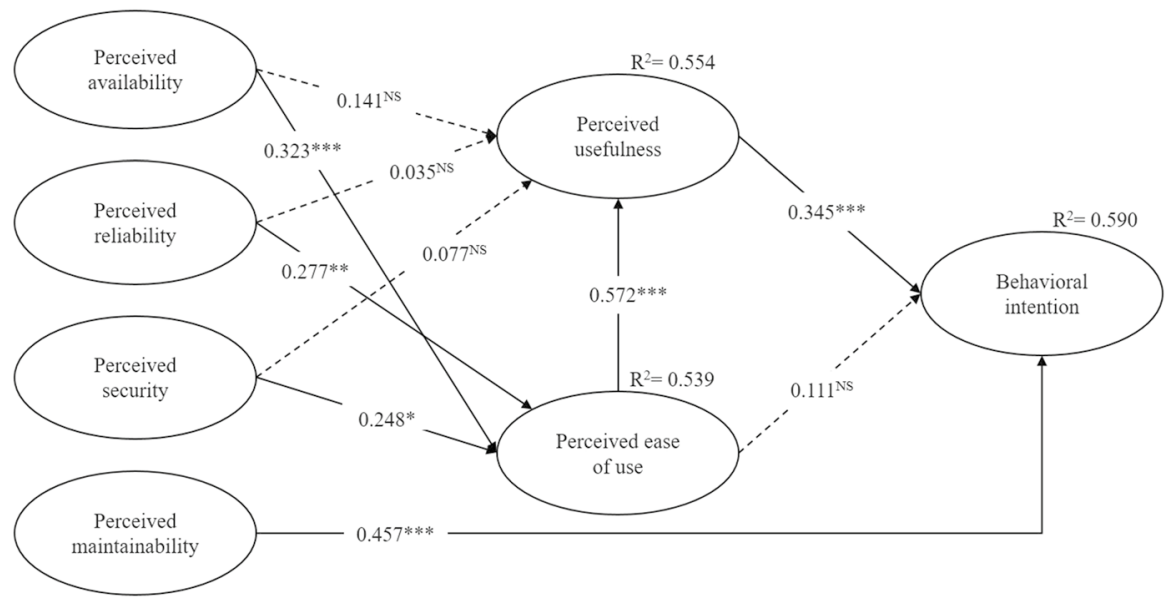

Fig. 3 Results of hypothesis test for full dataset. Notes. ${ }^{*} p<0.05$; $* p<0.01 ; * * * p<0.001$; NS $=$ not supported. Solid line: significant path; dashed line: non-significant path

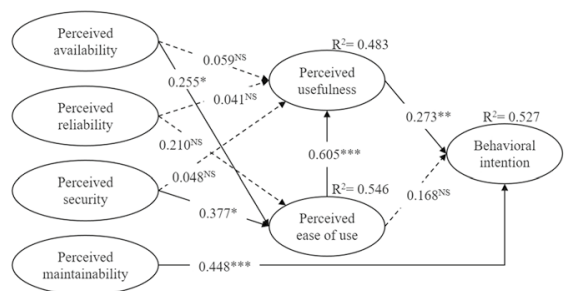

(a) High-IT-Intensive Industry (Hi-Iti)

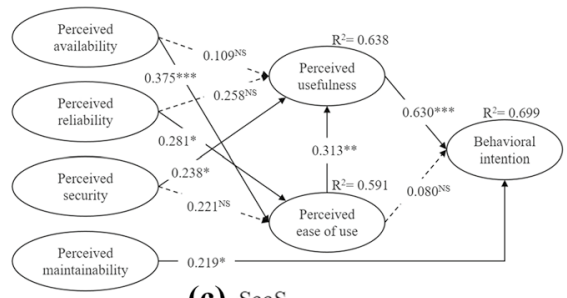

(c) SaaS

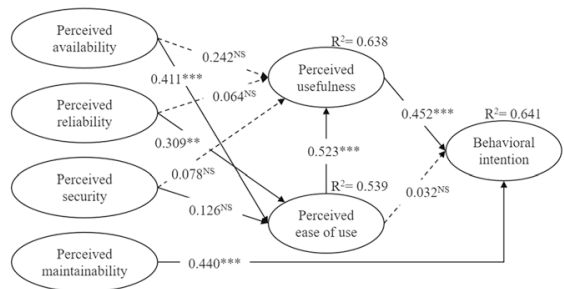

(b) Low-IT-Intensive Industry (Lo-Iti)

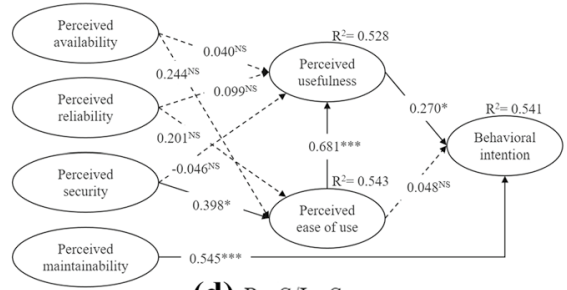

(d) PaaS/IaaS

Fig. 4 Results of hypothesis text for subgroups. Notes. ${ }^{*} p<0.05 ; * * p<0.01 ; * * *<0.001$; NS $=$ not supported. Solid line: significant path; dashed line: non-significant path

was significant for all groups (full data set: $\beta=0.457, p<0.001$; Hi-ITi: $\beta=0.448$, $p<0.001$; Lo-ITi: $\beta=0.440, p<0.001$; SaaS: $\beta=0.219, p<0.05$; PaaS/IaaS: $\beta=0.545, p<0.001)$; hence, $\mathrm{H} 10$ was accepted in all groups.

PAV, PRE, and PSE on perceived ease of use were significant for the full data set (for PAV: $\beta=0.323, p<0.001$; for PRE: $\beta=0.277, p<0.01$, for PSE: $\beta=0.248$, $p<0.05$ ); hence, H5, H7, and H9 were accepted in the full data set. However, their 


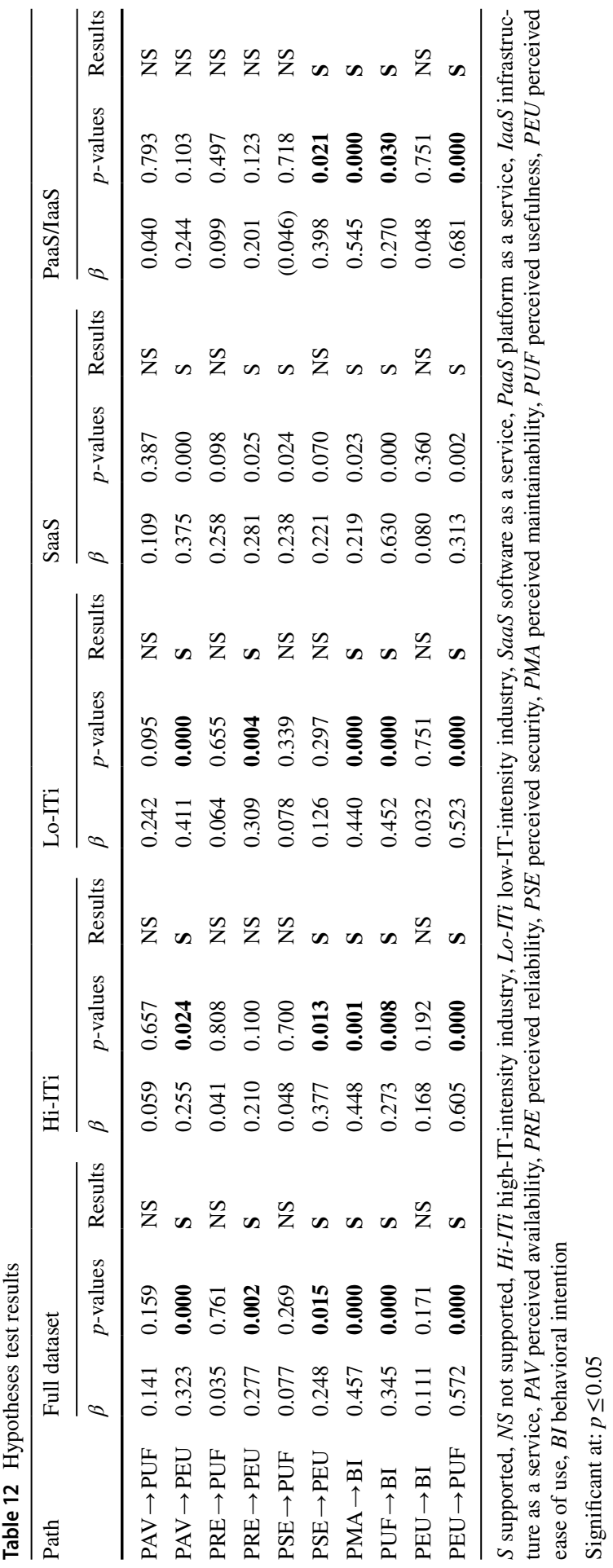


Table 13 Results of path differences

\begin{tabular}{|c|c|c|c|c|}
\hline \multirow[t]{2}{*}{ Path } & \multicolumn{2}{|c|}{ Hi-ITi versus Lo-ITi } & \multicolumn{2}{|c|}{ SaaS versus $\mathrm{PaaS} / \mathrm{IaaS}$} \\
\hline & $\begin{array}{l}\text { Path coeffi- } \\
\text { cients-diff }\end{array}$ & $p$-value & $\begin{array}{l}\text { Path coeffi- } \\
\text { cients-diff }\end{array}$ & $p$-value \\
\hline $\mathrm{PAV} \rightarrow \mathrm{PUF}$ & 0.183 & 0.821 & 0.069 & 0.355 \\
\hline $\mathrm{PAV} \rightarrow \mathrm{PEU}$ & 0.156 & 0.847 & 0.132 & 0.235 \\
\hline $\mathrm{PRE} \rightarrow \mathrm{PUF}$ & 0.023 & 0.546 & 0.158 & 0.224 \\
\hline $\mathrm{PRE} \rightarrow \mathrm{PEU}$ & 0.096 & 0.716 & 0.080 & 0.327 \\
\hline $\mathrm{PSE} \rightarrow \mathrm{PUF}$ & 0.030 & 0.580 & 0.284 & 0.042 \\
\hline $\mathrm{PSE} \rightarrow \mathrm{PEU}$ & 0.251 & 0.100 & 0.177 & 0.793 \\
\hline $\mathrm{PMA} \rightarrow \mathrm{BI}$ & 0.008 & 0.471 & 0.326 & 0.954 \\
\hline $\mathrm{PUF} \rightarrow \mathrm{BI}$ & 0.179 & 0.887 & 0.360 & 0.020 \\
\hline $\mathrm{PEU} \rightarrow \mathrm{BI}$ & 0.136 & 0.205 & 0.032 & 0.424 \\
\hline $\mathrm{PEU} \rightarrow \mathrm{PUF}$ & 0.083 & 0.324 & 0.368 & 0.951 \\
\hline
\end{tabular}

$\mathrm{Hi}$-ITi high-IT-intensity industry, Lo-ITi low-IT-intensity industry, SaaS software as a service, PaaS platform as a service, IaaS infrastructure as a service, $P A V$ perceived availability, $P R E$ perceived reliability, $P S E$ perceived security, $P M A$ perceived maintainability, $P U F$ perceived usefulness, $P E U$ perceived ease of use, $B I$ behavioral intention

path significance on perceived ease of use showed different results among comparison groups.

For both Hi-ITi and Lo-ITi, perceived ease of use was significantly determined by availability (Hi-ITi: $\beta=0.255, p<0.05$; Lo-ITi: $\beta=0.411, p<0.001$ ), so H5 was accepted. Perceived ease of use was not significantly determined by reliability in Hi-ITi, but it was in Lo-ITi $(\beta=0.309, p<0.01)$; H7 was rejected for HiITi, but accepted for Lo-ITi. Perceived ease of use was determined by security in Hi-ITi $(\beta=0.377, p<0.05)$, but not in Lo-ITi; so H9 was accepted for Hi-ITi, but not for Lo-ITi.

For both SaaS and PaaS/IaaS, perceived ease of use was significantly determined by availability $(\beta=0.375, p<0.001)$ and reliability $(\beta=0.281, p<0.05)$ in SaaS, but it did not in PaaS/IaaS. Hence, H5 and H7 were accepted for SaaS, but rejected for PaaS/IaaS. Perceived ease of use was not significantly determined by security in the SaaS, but was in the PaaS/IaaS $(\beta=0.398, p<0.05)$; hence H9 was rejected for SaaS, but accepted for PaaS/IaaS.

\subsection{Multi-group analysis}

This study included a multi-group analysis to identify whether path coefficients between comparison groups (Hi- ITi vs. Lo-ITi; SaaS vs. PaaS/IaaS) differ significantly (Table 13). No paths differed significantly between Hi-ITi and LoITi. Two paths differed significantly between SaaS and PaaS/IaaS: PSE $\rightarrow$ PUF $(\beta=0.284, p<0.05), \quad \mathrm{PUF} \rightarrow \mathrm{BI} \quad(\beta=0.360, p<0.05)$. The other five paths 
that showed different hypothesis results (i.e., Hi-ITi and Lo-ITi: PRE $\rightarrow$ PEU, $\mathrm{PSE} \rightarrow \mathrm{PEU} ; \mathrm{SaaS}$ and PaaS/IaaS: PAV $\rightarrow$ PEU, PRE $\rightarrow$ PEU, PSE $\rightarrow$ PEU) did not report significant differences between comparison groups.

\section{Discussion}

This study focuses on identifying the impact of dependability attributes in CC adoption in terms of intensity of IT use by industry and the type of CC. Combining the results in Table 12 (Figs. 3 and 4) with those in Tables 8, 9, 10, 11, and 13 reveals some interesting findings regarding dependability attributes and TAM constructs.

\subsection{TAM constructs}

TAM-related constructs showed the same results in all groups including the full dataset; this consistency confirms the fitness of our data for the TAM that was used as a baseline model.

Perceived usefulness directly affected behavioral intention to adopt $\mathrm{CC}$ in all groups including the full dataset. This influence was expected. Service type showed an interesting point: the differences in path coefficients between two groups were significant, i.e., manager' perception that $\mathrm{CC}$ is useful has more effect on the intention to use SaaS than to use PaaS. The reason might come from the inherent nature of SaaS, an individual-level service that is sensitive to the usefulness of a technology. This revelation shows that SaaS practitioners should pay more attention CC than PaaS/IaaS practitioners to maximizing the usefulness.

Perceived ease of use directly did not affect behavioral intention to adopt CC in all groups including the full dataset. The non-significance of the path between perceived ease of use and behavioral intention was not expected, and differs from the TAM's theoretical proposition [18, 29]. The difference might originate from the nature of $\mathrm{CC}$. In the context of organization, $\mathrm{CC}$ is a utilitarian technology that is intensively job-related. When a technology is used in a utilitarian type, the usefulness becomes more important than the ease of use [89]. This result is in line with some prior CC studies. Thus, although ease of use has traditionally been regarded as an important factor in the adoption of technology, it is not as important in the CC environment, in which the usefulness is more directly important than ease of use to the manager's perceptions of the benefit of adopting the technology. This revelation implies that practitioners must increase the usefulness of $\mathrm{CC}$ as much as possible, and that they do not have to focus on satisfying the ease of use of CC.

\subsection{Dependability attributes}

Availability attribute had similar influences across comparison groups (Hi-ITi vs. Lo-ITi; SaaS vs. PaaS/IaaS) including the full dataset. For both Hi-ITi and Lo-ITi, availability did not act as a direct antecedent of perceived usefulness, but did act as 
an antecedent of perceived ease of use. For both SaaS and PaaS/IaaS, availability had the same effect on perceived usefulness as that of IT Intensity by industry, but a different effect on perceived ease of use.

For CC service type, the path coefficients of availability on the ease of use seemed to be stronger among SaaS than among PaaS/IaaS. A possible explanation is that availability had less than a moderate effect on perceived ease of use in PaaS/ IaaS group $(\mathrm{PAV}=0.073)$. However, the multi-group analysis further showed no significant differences in path coefficients between $\mathrm{SaaS}$ and PaSS/IaaS, and the effect size did not differ between the two groups. These findings are valuable. This absence of difference stimulates the inference that availability may also serve to predict the ease of use of PaaS/IaaS depending on context factors such as technology type, user type and specific IT/IS context in each country (e.g., degree of technology maturity). Thus, this result suggests that even managers in PaaS/IaaS may evaluate the ease of use by considering whether $\mathrm{CC}$ is ubiquitous. Overall, these findings indicate that whether managers acquire ubiquitous connection does not affect their evaluation of the usefulness of CC, but may affect their evaluation of the ease of use by SaaS and PaaS/IaaS.

Reliability attribute also showed similar but different influences across comparison groups (Hi-ITi vs. Lo-ITi; SaaS vs. PaaS/IaaS) including the full dataset. Reliability did not act as a direct antecedent of perceived usefulness in any group. Reliability seemed to show different results in its relationship with perceived ease of use depending on IT intensity and service type: reliability had a positive effect on perceived ease of use for Lo-ITi, but no affect for Hi-ITi; it had a positive effected on perceived ease of use for SaaS, but not for PaaS/IaaS. The differences may be a result of the small effect size of reliability on perceived ease of use in the two groups (Hi-ITi: $f^{2}=0.035$; PaaS/IaaS: $f^{2}=0.036$ ).

However, the multi-group analysis further showed that the differences between path coefficients of comparison groups were not significant. These findings are interesting. This study infers that reliability may influence perceived ease of use for both Hi-ITi and PaaS/IaaS group. Thus, this indicates that managers do consider reliability when they assess the ease of use of CC in two groups. These interesting but controversial results require further investigation. Overall, these findings show that whether $\mathrm{CC}$ delivers its service reliably does not affect managers' evaluation of the usefulness of CC in all groups, but may affect their evaluation of its ease of use in all groups.

Security attribute had a complex influence as an antecedent of perceived usefulness and perceived ease of use. For Hi-ITi and Lo-ITi, security did not function as an antecedent of perceived usefulness, due to the small effect size (Hi-ITi: $f^{2}=0.002$; Lo-ITi: $\left.f^{2}=0.007\right)$. This lack of effect indicates that managers do not consider security when they assess the usefulness of CC. Security predicted ease of use in Hi-ITi, but not in Lo-ITi, but the multi-group analysis showed that the differences between path coefficients of comparison groups were not significant. This difference of conclusion is interesting, and indicates that security may affect perceived ease of use for Lo-ITi group; i.e., that managers may consider security when they assess the ease of use of CC in Lo-ITi group. 
For SaaS and PaaS/IaaS, security determined perceived usefulness for SaaS, but not for PaaS/IaaS; the difference was significant. This finding is informative, and shows that managers in SaaS evaluate the usefulness by evaluating whether CC is secure, but that managers in PaaS/IaaS do not. Security affected perceived ease of use in PaaS/IaaS, but not in SaaS, but the path coefficients did not differ between them. This results implies that managers' perception in SaaS group that CC is easy to use may be affected by the likelihood that its services are secure. Overall, these findings show that whether CC delivers its service securely does affect managers' evaluation of the usefulness of CC in SaaS group, but may affect their evaluation of its ease of use in all groups.

Maintainability was as a strong determinant for behavioral intention to adopt CC in all comparison groups (Hi- ITi vs. Lo-ITi; SaaS vs. PaaS/IaaS) including the full dataset. This is an unexpected result. Especially, service type showed an interesting point: the effect of maintainability on behavioral intention to adopt $\mathrm{CC}$ was more than twice as high in PaaS/IaaS $(\beta=0.545)$ than in SaaS, and PaaS/IaaS had the largest effect size $\left(f^{2}=0.446\right)$. The difference may originate from the differences in the natures of SaaS and PaaS/IaaS, and in the resources serviced. SaaS focuses on delivering individual-level services, whereas PaaS/IaaS focuses on organizationallevel services (e.g., development platform, hardware resources); this difference in focus may affect the perceptions of maintainability among business managers, because they tend to have a relatively enterprise-wide view, so maintainability may be perceived as more influential in PaaS/IaaS than in SaaS.

Furthermore, hardware maintenance differs from software maintenance [90]. Hardware wears out physically, and is generally not delivered with undiscovered flaws. However, software generally does include undiscovered flaws, but does not wear out physically. These characteristics of hardware resources may affect the managers' perceptions of maintainability. Overall, among three factors (perceived usefulness, perceived ease of use, maintainability) that directly affect behavioral intention to adopt $\mathrm{CC}$, maintainability has the largest effect size and strong path coefficient in all groups except SaaS.

\subsection{Additional information}

Considering the three dependability attributes (availability/reliability/security), one informative observation is that a non-path effect occurs between these attributes and perceived usefulness across all groups including the full dataset, except one path between security and perceived usefulness in SaaS. This observation contradicts the results of some studies in the literature review [25, 33, 76, 77, 87]. The reason may be a result of Korea's ubiquitous digital environment (i.e., 95.9\% penetration by the internet) [91], and its high internet connection speed (27 Mbps) [92], which four times the global average. Such an environment makes people in this country perceive that even $\mathrm{CC}$ services can be always used securely at anytime from anywhere without interruption. They also take this excellence for granted. This high exposure to the internet and the high expectation of a superior environment may account for availability/reliability/security having no significant effects on perceived usefulness. 
In contrast, SaaS showed a direct effect of security on usefulness. This path of influences may occur because SaaS focuses on delivering applications to users; SaaS users are sensitive to security concerns and are directly responsible for applicationlevel security [11].

Another observation is that three dependability attributes (availability/reliability/ security) affected the ease of CC for the full dataset. Their effects on the ease of CC seemed to differ across comparison groups. However, our study showed that most of these differences were not significant. In addition, among three factors (perceived usefulness, perceived ease of use, maintainability) that directly affect behavioral intention to adopt CC, maintainability has the largest effect size and strongest path coefficient in all groups except SaaS. This result suggests that practitioners recognize that maintainability attribute is a high-priority consideration by members of all groups in decisions to adopt $\mathrm{CC}$, except for SaaS where maintainability is the second-most-important consideration. From a technical and managerial standpoint, obstacles that hinder good maintenance of $\mathrm{CC}$ should be removed.

\section{Contribution and implication}

\subsection{Theoretical contribution}

This study makes several theoretical contributions to IT/IS research. First, the theoretical framework proposed in our study successfully synthesizes four dependability attributes (availability, reliability, security, maintainability) through the TAM. The research model for full data set explained $>=59 \%$ of the variance in the dependent variable, followed by SaaS group $\left(R^{2}=69.9 \%\right)$, Low-IT-Intensive Industry group $\left(R^{2}=64.1 \%\right)$, PaaS/IaaS group $(54.1 \%)$, and High-IT-Intensive Industry group $\left(R^{2}=0.527 \%\right)$. Overall, our research models showed high predictive powers when compared to those of TAM $\left(40 \% \leq R^{2} \leq 50 \%\right)$.

Especially, by introducing dependability as a multi-dimensional notion, this study offers a fresh theoretical approach concerning CC acceptance in the organizational context. This is the first research that integrates dependability attributes with technology acceptance theory. Previous studies have overlooked the effect of dependability attributes on $\mathrm{CC}$ adoption. The observation deserves academic attention because no other research has considered the multi-dimensional approach to dependability. Overall, this study identifies the mechanism by which individual dependability attributes works in the CC context according to IT intensity and service type.

Second, this study advances the existing knowledge base related to IS/IT technology adoption. This is because our study identifies the similarities and differences in the importance of dependability to managers in industries that have different levels of dependence on IT and different requirements for $\mathrm{CC}$ service. This study further performed multi- group analysis beyond traditional hypothesis testing, by conducting path differences and effect size differences. The importance of maintainability is also noteworthy: it is a strong determinant of CC adoption in all groups. Availability, reliability and security do not differ significantly between high and low IT-intensive industries, but differs slightly between SaaS and PaaS/IaaS. Especially, security 
significantly differs by service type. Regarding the core TAM constructs, perceived usefulness significantly influences CC adoption in all groups, whereas perceived ease of use does not in all groups. One interesting point is that perceived usefulness significantly differs by service type.

Third, this study advances the existing literature in terms of sample diversity. Our literature review revealed a scarcity of studies that targeted business managers. Among specific user groups in an organization, managers deserve attention for research, because they have an important role in recognizing the value of a new technology, and in adopting and implementing the technology within an organization [93]. Especially, in an organization they control information transfer because they bridge between employees and top management [94]. Moreover, a huge decision to invest, such as introducing CC, is not made solely by IT/IS managers [95]. For example, application of CC is enterprise-wide, so the decision to migrate an existing system to $\mathrm{CC}$ is affected by various managers [96] including functional managers (e.g., service manager). Despite the importance of a manager's role in embracing new technologies, prior studies have failed to consider it. Thus, this study enhances the diversity of target population in CC technology acceptance.

\subsection{Industrial implications}

This study practically makes three implications for business. The first is for cloud service providers such as CSPs. This study shows that the usefulness of CC is an important determinant in all groups, whereas the ease is not. This distinction implies that cloud service providers must consider usefulness of CC more than its ease of use when delivering the cloud services.

This study has also shown that three attributes of dependability (availability, reliability, security) do not differ significantly between high and low IT-intensive industry groups, but differs between SaaS and PaaS/IaaS group. Maintainability is found to be an important predictor of CC adoption across all groups, but the priority varies by service type. For example, maintainability is a high-priority consideration by members of all groups in decisions to adopt $\mathrm{CC}$, but it is the second most important consideration in the SaaS group. This difference suggests that CC service providers must either take the same market approach or take a different market approach, depending on the type of customer. Thus, $\mathrm{CC}$ service providers should consider each characteristic of the dependability attribute according to the customer type when retaining current business customers and attracting new ones.

The third is for CC service consumers such as business firms. This study shows that the CC service type to be introduced is a more important consideration than the type of industry to which one belongs. In particular, managers' perceptions of security, maintainability and usefulness differed according to the service type, but not according to IT intensity. For example, the usefulness of CC is the most important consideration for the SaaS group, while maintain-ability is the most important consideration for Pass/IaaS group. Security is an important factor for SaaS users, but not for PaaS/IaaS users. This comparison indicates that when designing and introducing $\mathrm{CC}$ for their organizations, 
industrial practitioners must prioritize considerations differently depending on the type of CC service.

\section{Limitations and future research}

This research had some limitations. The first comes from the simplicity of our baseline model; the simplicity can limit the generalizability of the findings. This simplicity is both an advantage and a disadvantage. One of the most widely known criticisms is that TAM does not consider external and internal drivers such as price and subjective norm [34], Despite this objection, we used TAM because we focused on how dependability attributes work with two key factors (i.e., usefulness, ease of use) that are generally accepted as the strongest predictors of behavioral intention in the IT/IS research area. Therefore, researchers are encouraged to conduct a similar research method using other theoretical models (e.g., TOE, UTAUT), and to include additional variables.

Second, we ignored other dependability attributes such as performability, testability, integrity and confidentiality. We extracted four overlapping attributes of dependability from several classifications by other researchers, and applied these attributes to our study. Future research should consider other types of dependability attributes to increase the completeness of the integration between dependability notion and technology acceptance theory.

Third, we did not overcome data bias. Data of respondents were gathered from a specific country that has a superior digital environment. Thus, the findings may vary among countries, depending on the IT/IS contexts; i.e., the effect of dependability on CC acceptance may be different in countries that have superior digital environments than in countries that have inferior digital environments. Furthermore, this is a cross-sectional study. The study focused on a specific-level group within an organization, but managers are exposed to internal and external information, possibly more than other specific groups of users, so managers' perceptions of CC may be more likely to change over time than those of such other groups. Moreover, dependability attributes change over time with respect to system performance [14]. Thus, an inter-country comparative study and longitudinal study with a similar research approach might be informative.

\section{Conclusion}

This study identified the influence of dependability attributes (availability, reliability, security, maintainability) on adoption of $\mathrm{CC}$ in the context of organization. To do this, we combined dependability attributes with TAM and test it with the data collected from business managers in South Korea. This study used PLS-SEM to validate the proposed research model, and then conducted multigroup analysis in terms of IT intensity and service type, along with testing casualties among constructs. Overall, the intention to accept $\mathrm{CC}$ was affected by its 
usefulness, not by its ease of use. Interestingly, maintainability was a strong predictor of the intention to accept CC. For comparison groups, we showed how similarities and differences between groups of managers depend on the intensity of IT and the type of CC that they use. Managers' perceptions of dependability attributes and TAM variables in adopting CC to their organizations did not differ between industries with high IT intensity and those with low IT intensity. However, for SaaS and PaaS/IaaS, managers showed differences in their perceptions of the effect of the usefulness on the intention to adopt CC, and the effect of security on perceived usefulness of TAM variables. Maintainability is a strong determinant of $\mathrm{CC}$ adoption in all groups except SaaS. The findings can provide academic researchers and industry practitioners with in-depth perspective on the understanding and the spread of CC. In particular, our results that were obtained using behavioral theory give $\mathrm{CC}$ developers a differentiated perspective on how to facilitate successful CC implementation.

\section{Appendix 1: Measurement items}

\begin{tabular}{|c|c|c|c|}
\hline Construct & & Measurement items & \\
\hline Perceived availability & PAV1 & $\begin{array}{l}\text { In organization affairs, CC pro- } \\
\text { viding accessibility "anytime- } \\
\text { and-anywhere" is very crucial }\end{array}$ & $\begin{array}{l}\text { Arpaci [74]; Gangwar and Date } \\
\text { [25]; Tripathi [48] }\end{array}$ \\
\hline & PAV2 & $\begin{array}{l}\text { Employee can access to CC any- } \\
\text { time for the necessary service }\end{array}$ & \\
\hline & PAV3 & $\begin{array}{l}\text { Employee can access to CC } \\
\text { anywhere for the necessary } \\
\text { service }\end{array}$ & \\
\hline & PAV4 & $\begin{array}{l}\text { Overall, employee can use CC } \\
\text { "anywhere", "anytime" at the } \\
\text { point of need }\end{array}$ & \\
\hline Perceived reliability & PRE1 & $\mathrm{CC}$ service are reliable & Sintonen and Immonen [75]; Tella \\
\hline & PRE2 & $\begin{array}{l}\text { CC operates reliably without } \\
\text { interruption (e.g., shutdown) }\end{array}$ & et al. [8] \\
\hline & PRE3 & $\begin{array}{l}\mathrm{CC} \text { would reduce burden of } \\
\text { various hazards (e.g.; fire, } \\
\text { flooding) }\end{array}$ & \\
\hline & PRE4 & $\begin{array}{l}\text { Overall, } \mathrm{CC} \text { is as reliable as on- } \\
\text { premise systems }\end{array}$ & \\
\hline Perceived security & PSE1 & $\begin{array}{l}\text { In } \mathrm{CC} \text {, data is safeguarded from } \\
\text { unauthorized changes or use }\end{array}$ & $\begin{array}{l}\text { Yousafzai et al. [78]; Goode et al. } \\
\text { [79]; Safari et al. [49] }\end{array}$ \\
\hline & PSE2 & $\begin{array}{l}\text { In CC, data is protected from } \\
\text { those who should not have } \\
\text { access to it }\end{array}$ & \\
\hline & PSE3 & $\begin{array}{l}\mathrm{CC} \text { has proper anti-virus protec- } \\
\text { tion }\end{array}$ & \\
\hline & PSE4 & $\begin{array}{l}\text { Overall, cloud computing is as } \\
\text { secure as on-premise systems }\end{array}$ & \\
\hline
\end{tabular}




\begin{tabular}{|c|c|c|c|}
\hline Construct & & Measurement items & \\
\hline \multirow[t]{4}{*}{ Perceived maintainability } & PMA1 & $\begin{array}{l}\mathrm{CC} \text { would reduce burden of } \\
\text { hardware maintenance }\end{array}$ & Developed by researcher \\
\hline & PMA2 & $\begin{array}{l}\mathrm{CC} \text { would reduce burden of } \\
\text { software maintenance }\end{array}$ & \\
\hline & PMA3 & $\begin{array}{l}\mathrm{CC} \text { would reduce operational } \\
\text { burden of IS/IT resources }\end{array}$ & \\
\hline & PMA4 & $\begin{array}{l}\text { Overall, cloud computing is as } \\
\text { easy to maintain as on-premise } \\
\text { systems }\end{array}$ & \\
\hline \multirow[t]{6}{*}{ Perceived usefulness } & PUF1 & $\begin{array}{l}\text { Using CC in organization affairs } \\
\text { would enable employee to } \\
\text { accomplish tasks more quickly }\end{array}$ & $\begin{array}{l}\text { Davis [28]; Venkatesh and } \\
\text { Davis[29]; Venkatesh et al. [18] }\end{array}$ \\
\hline & PUF2 & $\begin{array}{l}\text { Using CC would improve } \\
\text { employees' job performance }\end{array}$ & \\
\hline & PUF3 & $\begin{array}{l}\text { Using CC in my job would } \\
\text { increase employees' produc- } \\
\text { tivity }\end{array}$ & \\
\hline & PUF4 & $\begin{array}{l}\text { Using CC would enhance } \\
\text { employees' effectiveness on } \\
\text { the job }\end{array}$ & \\
\hline & PUF5 & $\begin{array}{l}\text { Using CC would make it easier } \\
\text { to do employees' job }\end{array}$ & \\
\hline & PUF6 & $\begin{array}{l}\text { I would find CC useful in } \\
\text { employees' job }\end{array}$ & \\
\hline \multirow[t]{5}{*}{ Perceived ease of use } & PUE1 & $\begin{array}{l}\text { Learning to operate } \mathrm{CC} \text { would } \\
\text { be easy for employee }\end{array}$ & \\
\hline & PUE2 & $\begin{array}{l}\text { I would find it easy to get } \mathrm{CC} \\
\text { to do what employee want it } \\
\text { to do }\end{array}$ & \\
\hline & PUE3 & $\begin{array}{l}\text { Interaction with } \mathrm{CC} \text { would be } \\
\text { clear and understandable }\end{array}$ & \\
\hline & PUE4 & $\begin{array}{l}\text { It would be easy for employee to } \\
\text { become skillful at using CC }\end{array}$ & \\
\hline & PUE5 & I would find CC easy to use & \\
\hline \multirow[t]{4}{*}{ Behavioral intention } & BI1 & $\begin{array}{l}\text { My organization plans to use } \\
\text { CC in the future }\end{array}$ & \\
\hline & BI2 & $\begin{array}{l}\text { My organization intends to use } \\
\text { CC as much as possible }\end{array}$ & \\
\hline & BI3 & $\begin{array}{l}\text { It is worth using } \mathrm{CC} \text { in my } \\
\text { organization }\end{array}$ & \\
\hline & $\mathrm{BI} 4$ & $\begin{array}{l}\text { My organization will continue } \\
\text { to use CC if we have access to } \\
\text { the services }\end{array}$ & \\
\hline
\end{tabular}

$C C$ cloud computing, $P A V$ perceived availability, $P R E$ perceived reliability, $P S E$ perceived security, $P M A$ perceived maintainability, $P U F$ perceived usefulness, $P E U$ perceived ease of use, $B I$ behavioral intention 


\section{Appendix 2: Sample profiles}

\begin{tabular}{|c|c|c|}
\hline Respondents profiles $(n=230)$ & Frequency & Percentage $(\%)$ \\
\hline \multicolumn{3}{|l|}{ Job experiences } \\
\hline $2-5$ years & 30 & 13.0 \\
\hline $6-10$ years & 83 & 36.1 \\
\hline 11 years $\sim$ & 117 & 50.9 \\
\hline \multicolumn{3}{|l|}{ Job positions } \\
\hline First-line manager & 113 & 49.1 \\
\hline Middle-line manager & 108 & 47.0 \\
\hline Senior manager & 9 & 3.9 \\
\hline \multicolumn{3}{|l|}{ Main tasks } \\
\hline Production & 25 & 10.9 \\
\hline Marketing/Sales & 21 & 9.1 \\
\hline $\begin{array}{l}\text { Management (strategy/planning, organization/HR, } \\
\text { financing/procurement) }\end{array}$ & 106 & 46.1 \\
\hline $\mathrm{R} \& \mathrm{D}$ & 22 & 9.6 \\
\hline IT & 56 & 24.3 \\
\hline Organization profiles $(n=230)$ & Frequency & Percentage $(\%)$ \\
\hline \multicolumn{3}{|l|}{ Main industry } \\
\hline Manufacturing & 69 & 30.0 \\
\hline Energy/chemicals/utilities & 10 & 4.3 \\
\hline Engineering & 17 & 7.4 \\
\hline Financing & 7 & 3.0 \\
\hline IT & 45 & 19.6 \\
\hline Telecommunications & 9 & 3.9 \\
\hline Wholesale/retails & 17 & 7.4 \\
\hline Government/public area & 27 & 11.7 \\
\hline Service & 29 & 12.6 \\
\hline \multicolumn{3}{|l|}{ Business scope } \\
\hline Global business & 61 & 26.5 \\
\hline Domestic business & 158 & 68.7 \\
\hline Local business & 11 & 4.8 \\
\hline \multicolumn{3}{|l|}{ Employee size } \\
\hline$<300$ & 116 & 50.4 \\
\hline $300-1000$ & 87 & 37.8 \\
\hline$>1000$ & 27 & 11.7 \\
\hline \multicolumn{3}{|l|}{ Sales $(K R W)$} \\
\hline$<1$ billion & 26 & 11.3 \\
\hline $1-5$ billion & 42 & 18.3 \\
\hline 5-10 billion & 29 & 12.6 \\
\hline $10-50$ billion & 45 & 19.6 \\
\hline $50-2$ trillion & 41 & 17.8 \\
\hline
\end{tabular}




\begin{tabular}{lcc}
\hline Organization profiles $(n=230)$ & Frequency & Percentage $(\%)$ \\
\hline $2-5$ trillion & 23 & 10.0 \\
$5-10$ trillion & 6 & 2.6 \\
$>10$ trillion & 18 & 7.8 \\
\hline
\end{tabular}

$K R W$ Korean Won

\section{Appendix 3: Measurement invariance test}

\begin{tabular}{|c|c|c|c|c|}
\hline \multirow[t]{2}{*}{ Construct and indicators } & \multicolumn{2}{|l|}{ Hi-ITi versus Lo-ITi } & \multicolumn{2}{|c|}{ SaaS versus PaaS/IaaS } \\
\hline & Outer loadings-diff & $p$-value & Outer loadings-diff & $p$-value \\
\hline $\mathrm{BI} 1 \leftarrow \mathrm{BI}$ & 0.024 & 0.793 & 0.028 & 0.793 \\
\hline $\mathrm{BI} 2 \leftarrow \mathrm{BI}$ & 0.077 & 0.976 & 0.064 & 0.166 \\
\hline $\mathrm{BI} 3 \leftarrow \mathrm{BI}$ & 0.005 & 0.452 & 0.007 & 0.583 \\
\hline $\mathrm{BI} 4 \leftarrow \mathrm{BI}$ & 0.012 & 0.661 & 0.051 & 0.923 \\
\hline $\mathrm{PAV} 1 \leftarrow \mathrm{PAV}$ & 0.104 & 0.972 & 0.049 & 0.245 \\
\hline $\mathrm{PAV} 2 \leftarrow \mathrm{PAV}$ & 0.029 & 0.832 & 0.023 & 0.727 \\
\hline $\mathrm{PAV} 3 \leftarrow \mathrm{PAV}$ & 0.026 & 0.236 & 0.021 & 0.331 \\
\hline $\mathrm{PAV} 4 \leftarrow \mathrm{PAV}$ & 0.029 & 0.194 & 0.025 & 0.264 \\
\hline $\mathrm{PEU} 1 \leftarrow \mathrm{PEU}$ & 0.031 & 0.760 & 0.027 & 0.687 \\
\hline $\mathrm{PEU} 2 \leftarrow \mathrm{PEU}$ & 0.001 & 0.493 & 0.002 & 0.535 \\
\hline $\mathrm{PEU} 3 \leftarrow \mathrm{PEU}$ & 0.003 & 0.458 & 0.023 & 0.803 \\
\hline $\mathrm{PEU} 4 \leftarrow \mathrm{PEU}$ & 0.017 & 0.722 & 0.050 & 0.908 \\
\hline PEU5 $\leftarrow$ PEU & 0.011 & 0.350 & 0.032 & 0.775 \\
\hline PMA1 & 0.004 & 0.540 & 0.004 & 0.535 \\
\hline PMA2 $\leftarrow$ PMA & 0.058 & 0.924 & 0.020 & 0.665 \\
\hline PMA3 $\leftarrow$ PMA & 0.033 & 0.768 & 0.007 & 0.571 \\
\hline $\mathrm{PMA} 4 \leftarrow \mathrm{PMA}$ & 0.051 & 0.773 & 0.003 & 0.513 \\
\hline PRE1 $\leftarrow$ PRE & 0.007 & 0.564 & 0.032 & 0.264 \\
\hline $\mathrm{PRE} 2 \leftarrow \mathrm{PRE}$ & 0.047 & 0.871 & 0.050 & 0.167 \\
\hline $\mathrm{PRE} 3 \leftarrow \mathrm{PRE}$ & 0.018 & 0.599 & 0.080 & 0.842 \\
\hline $\mathrm{PRE} 4 \leftarrow \mathrm{PRE}$ & 0.040 & 0.809 & 0.035 & 0.272 \\
\hline $\mathrm{PSE} 1 \leftarrow \mathrm{PSE}$ & 0.033 & 0.254 & 0.073 & 0.065 \\
\hline $\mathrm{PSE} 2 \leftarrow \mathrm{PSE}$ & 0.023 & 0.730 & 0.025 & 0.284 \\
\hline $\mathrm{PSE} 3 \leftarrow \mathrm{PSE}$ & 0.017 & 0.641 & 0.012 & 0.600 \\
\hline $\mathrm{PSE} 4 \leftarrow \mathrm{PSE}$ & 0.012 & 0.635 & 0.010 & 0.638 \\
\hline $\mathrm{PUF} 3 \leftarrow \mathrm{PUF}$ & 0.005 & 0.449 & 0.021 & 0.696 \\
\hline $\mathrm{PUF} 4 \leftarrow \mathrm{PUF}$ & 0.051 & 0.801 & 0.029 & 0.344 \\
\hline $\mathrm{PUF} 5 \leftarrow \mathrm{PUF}$ & 0.035 & 0.131 & 0.076 & 0.968 \\
\hline PUF6 $\leftarrow$ PUF & 0.036 & 0.152 & 0.033 & 0.817 \\
\hline
\end{tabular}

Hi-ITi High-IT-intensity industry, Lo-ITi Low-IT-intensity industry, SaaS software as a service, PaaS platform as a service, IaaS infrastructure as a service, $P A V$ perceived availability, $P R E$ perceived reliability, $P S E$ perceived security, $P M A$ perceived maintainability, $P U F$ perceived usefulness, $P E U$ perceived ease of use, $B I$ behavioral intention. 


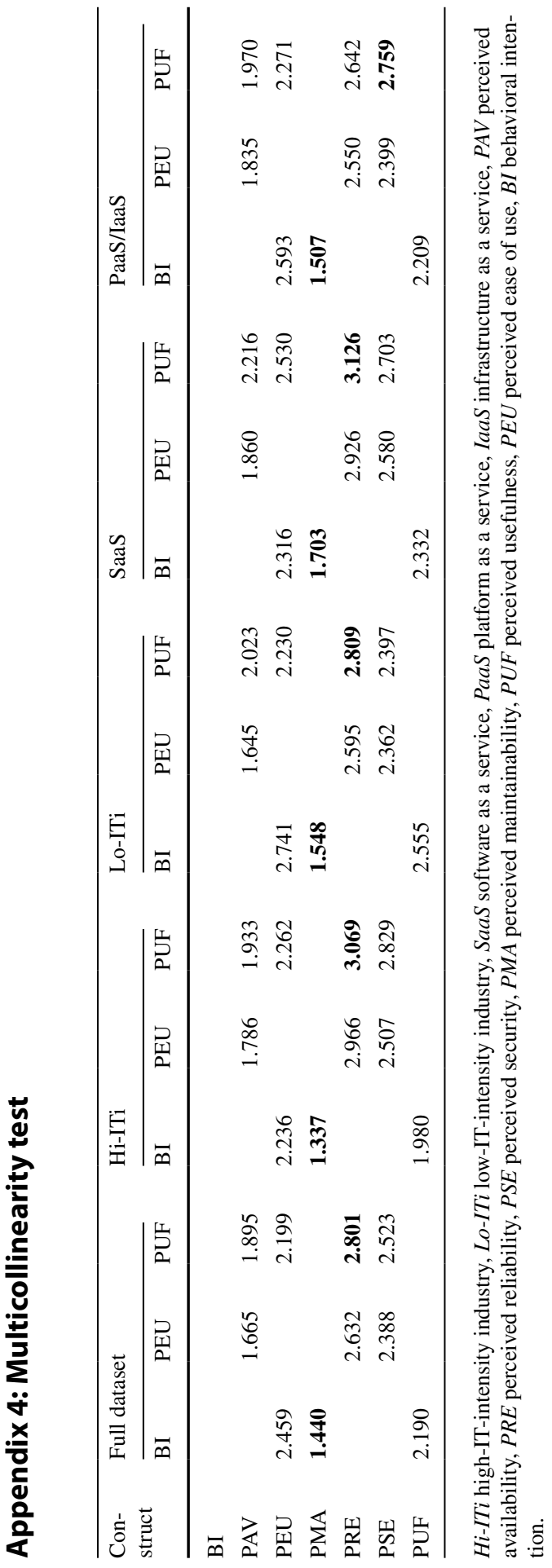


Funding Not applicable.

Data availability The dataset supporting the conclusions of this article is available in the Mendeley Data repository, and hyperlink to dataset in https://doi.org/10.17632/mgd4h2vnzd.8.

\section{Declarations}

Conflict of interest The authors declare that they have no competing interests.

Open Access This article is licensed under a Creative Commons Attribution 4.0 International License, which permits use, sharing, adaptation, distribution and reproduction in any medium or format, as long as you give appropriate credit to the original author(s) and the source, provide a link to the Creative Commons licence, and indicate if changes were made. The images or other third party material in this article are included in the article's Creative Commons licence, unless indicated otherwise in a credit line to the material. If material is not included in the article's Creative Commons licence and your intended use is not permitted by statutory regulation or exceeds the permitted use, you will need to obtain permission directly from the copyright holder. To view a copy of this licence, visit http://creativecommons.org/licen ses/by/4.0/.

\section{References}

1. Knight J (2012) Fundamentals of dependable computing for software engineers. Chapman \& Hall/ CRC Press, Boca Raton

2. Johnson BW (1989) Design and analysis of fault tolerant digital systems. Addison-Wesley Publishing Company Inc, Boston

3. Avizienis A, Laprie JC, Randell B, Landwehr C (2004) Basic concepts and taxonomy of dependable and secure computing. IEEE Trans Dependable Secure Comput 1(1):11-33. https://doi.org/10.1109/ TDSC.2004.2

4. Lai JY, Yang CC (2009) Effects of employees' perceived dependability on success of enterprise applications in e- business. Ind Mark Manage 38:263-274. https://doi.org/10.1016/j.indmarman. 2008.01.002

5. Mc Geough B, Donnellan B (2013) Factors that affect the adoption of cloud computing for an enterprise: a case study of cloud adoption within intel corporation. In: Proceedings of the 21st European Conference on Information Systems, 2013, pp 1-12. ECIS. http://aisel.aisnet.org/ecis2013_cr/37

6. Adjei JK, Adams S, Mamattah L (2021) Cloud computing adoption in Ghana; accounting for institutional factors. Technol Soc 65:1-9. https://doi.org/10.1016/j.techsoc.2021.101583

7. Ali O, Shrestha A, Ghasemaghaei M, Beydoun G (2021) Assessment of complexity in cloud computing adoption: a case study of local governments in Australia. Inf Syst Front. https://doi. org/10.1007/s10796-021-10108-w

8. Tella A, Ukwoma SC, Kayode AI (2020) A two models modification for determining cloud computing adoption for web-based services in academic libraries in Nigeria. J Acad Librariansh 46:1-15. https://doi.org/10.1016/j.acalib.2020.102255

9. Jahangiri P, Saberi MK, Vakilimofrad H (2021) Development and psychometric evaluation of the cloud computing acceptance questionnaire for academic libraries. J Acad Librariansh 47:1-11. https://doi.org/10.1016/j.acalib.2021.102395

10. Hogan M, Liu F, Sokol A, Tong J (2011) NIST cloud computing standards roadmap. National Institute of Standards and Technology. https://www.nist.gov/system/files/documents/itl/cloud/ NIST_SP-500-291_Ju15A.pdf. Accessed 5 June 2021

11. Armbrust M, Fox A, Griffith R, Joseph AD, Katz R, Konwinski A, Lee G, Patterson D, Rabkin A, Stoica I, Zaharia M (2010) A view of cloud computing. Commun ACM 53(4):50-58. https:// doi.org/10.1145/1721654.1721672

12. Tian L, Lin C, Ni Y (2010) Evaluation of user behavior trust in cloud computing. Int Conf Comput Appl Syst Model 7:567-572. https://doi.org/10.1109/ICCASM.2010.5620636

13. Tomas S, Thomas M, Oliveira T (2018) Evaluating the impact of virtualization characteristics on SaaS adoption. Enterp Inf Syst 12(3):259-278. https://doi.org/10.1080/17517575.2017.1355484 
14. Pan Y, Hu N (2014) Research on dependability of cloud computing systems. In: International Conference on Reliability, Maintainability and Safety, 2014, pp 435-439. IEEE. https://doi.org/ 10.1109/ICRMS.2014.7107234

15. Shahzad A, Litchfield A (2015) Virtualization technology: cross-VM cache side channel attacks make it vulnerable. In: Proceedings of Australasian Conference on Information Systems, 2015, pp 1-14. ACIS. https://aisel.aisnet.org/acis2015/120

16. Branco TJ, Sá-Soares F, Riverob AL (2017) Key issues for the successful adoption of cloud computing. Proc Comput Sci 121:115-122. https://doi.org/10.1016/j.procs.2017.11.016

17. Russo S, Vieira M (2017) Security and dependability of cloud systems and services. IEEE Trans Serv Comput 10:673-674. https://doi.org/10.1109/TSC.2017.2735778

18. Venkatesh V, Morris MG, Davis GB, Davis FD (2003) User acceptance of information technology: toward a unified view. MIS Q 27(3):425-478. https://doi.org/10.2307/30036540

19. Taherdoost H (2019) Importance of technology acceptance assessment for successful implementation and development of new technologies. Glob J Eng Sci 1(3):1-4. https://doi.org/10.33552/ GJES.2019.01.000511

20. Tripathi S (2017) Understanding the determinants affecting the continuance intention to use cloud computing. J Int Technol Inf Manage 26(3):124-152

21. Momani AM, Jamous MM, Hilles SMS (2017) Technology acceptance theories: review and classification. Int J Cyber Behav, Psychol Learn 7(2):1-14. https://doi.org/10.4018/IJCBPL.20170 40101

22. Matar N, AlMalahmeh T, Al-Adaileh M, Al Jaghoub S (2020) Factors affecting behavioral intentions towards cloud computing in the workplace. Int J Emer Technol Learn 15(16):31-48

23. Richter NF, Sinkovics RR, Ringle CM, Schlägel C (2016) A critical look at the use of SEM in international business research. Int Mark Rev 33(3):376-404. https://doi.org/10.1108/ IMR-04-2014-0148

24. Risher J, Ringle CM, Sarstedt M (2019) When to use and how to report the results of PLS-SEM. Eur Bus Rev 31(1):2-24. https://doi.org/10.1108/EBR-11-2018-0203

25. Gangwar H, Date H, Ramaswamy R (2015) Understanding determinants of cloud computing adoption using an integrated TAM-TOE model. J Enterp Inf Manag 28(1):107-130. https://doi.org/10. 1108/JEIM-08-2013-0065

26. Palos-Sanchez PR, Arenas-Marquez FJ, Aguayo-Camacho M (2017) Cloud computing (SaaS) adoption as a strategic technology: results of an empirical study. Mob Inf Syst 1:1-20. https://doi.org/10. $1155 / 2017 / 2536040$

27. Gangwar H, Date H (2016) Critical factors of cloud computing adoption in organizations: an empirical study. Glob Bus Rev 17(4):886-904. https://doi.org/10.1177/0972150916645692

28. Davis FD (1989) Perceived usefulness, perceived ease of use, and user acceptance of information technology. MIS Q 13(3):319-340. https://doi.org/10.2307/249008

29. Venkatesh V, Davis FD (1996) A model of the antecedents of perceived ease of use: development and test. Decis Sci 27(3):451-481. https://doi.org/10.1111/j.1540-5915.1996.tb00860.x

30. Henseler J, Ringle CM, Sarstedt M (2015) A new criterion for assessing discriminant validity in variance-based structural equation modeling. J Acad Mark Sci 43:115-135. https://doi.org/10.1007/ s11747-014-0403-8

31. Sabi HM, Uzoka FME, Langmia K, Njeh FN, Tsuma CK (2017) A cross-country model of contextual factors impacting cloud computing adoption at universities in sub-Saharan Africa. Inf Syst Front 20:1381-1404. https://doi.org/10.1007/s10796-017-9739-1

32. Oliveira T, Martins R, Sarker S, Thomas M, Popovic ${ }^{2}$ A (2019) Understanding SaaS adoption: the moderating impact of the environment context. Int J Inf Manage 49:1-12. https://doi.org/10.1016/j. ijinfomgt.2019.02.009

33. Al-Jabri IM, Alabdulhadi MH (2016) Factors affecting cloud computing adoption: perspectives of IT professionals. Int J Bus Inf Syst 23(4):389-405. https://doi.org/10.1504/IJBIS.2016.080215

34. Hsieh PJ, Lin WS (2018) Explaining resistance to system usage in the PharmaCloud: a view of the dual-factor model. Inf Manage 55(1):51-63. https://doi.org/10.1016/j.im.2017.03.008

35. Li C, Raghunathan A, Jha NK (2012) A trusted virtual machine in an untrusted management environment. IEEE Trans Serv Comput 5(4):472-483. https://doi.org/10.1109/TSC.2011.30

36. Chen LY (2017) Perceived risk and trust in the adoption of cloud computing services and their effects on organizational performance. Int J Adv Stud Comput Sci Eng 6(5):24-31 
37. Wang G, Chen S, Liu J (2015) An environment-aware anomaly detection framework of cloud platform for improving its dependability. In: Proceedings of the International Conference on Parallel and Distributed Processing Techniques and Applications, 2015, pp 431-437. WorldComp

38. Cengiz E, Bakirta H (2020) Technology acceptance model 3 in understanding employee's cloud computing technology. Glob Bus Rev. https://doi.org/10.1177/0972150920957173

39. Park SC, Ryoo SY (2013) An empirical investigation of end-users' switching toward cloud computing: a two factor theory perspective. Comput Hum Behav 29:160-170. https://doi.org/10.1016/j.chb. 2012.07.032

40. Capek J (2010) Dependability of E-information sources. IntechOpen, London

41. Chavez F (2015) Cloud-based soft real-time systems for monitoring and controlling distributed industrial operations: a feasibility study. Dissertation, Colorado Technical University

42. Guan Q, Chiu CC, Fu S (2012) CDA: a cloud dependability analysis framework for characterizing system dependability in cloud computing infrastructures. In: Proceedings of 18th Pacific Rim International Symposium on Dependable Computing, 2012, pp 11-20. IEEE. https://doi.org/10.1109/ PRDC.2012.10

43. Fitzgerald KJ (1995) Information security baselines. Inf Manag Comput Secur 3(2):8-12. https:// doi.org/10.1108/09685229510088575

44. Littlewood B, Strigini L (2000) Software reliability and dependability: a Roadmap. In: Proceedings of the Conference on the Future of Software Engineering, 2000, pp 177-188. ACM

45. Khan MA, Kerkhoff HG (2013) Monitoring operating temperature and supply voltage in achieving high system dependability. In: Proceedings of 8th International Conference on Design \& Technology of Integrated Systems in Nanoscale Era, pp 108-112. IEEE

46. Lai JY, Chen WH (2009) Measuring e-business dependability: the employee perspective. J Syst Softw 82:1046-1055. https://doi.org/10.1016/j.jss.2009.02.029

47. Cho V, Chan A (2015) An integrative framework of comparing SaaS adoption for core and non-core business operations: an empirical study on Hong Kong industries. Inf Syst Front 17(3):629-644. https://doi.org/10.1007/s10796-013-9450-9

48. Tripathi S (2019) Determinants of cloud computing adoption: a comparative study. Pac Asia J Assoc Inf Syst 11(3):28-54. https://doi.org/10.17705/1pais.11303

49. Safari F, Safari N, Hasanzadeh A (2015) The adoption of software-as-a-service (SaaS): ranking the determinant. J Enterp Inf Manag 28(3):400-422. https://doi.org/10.1108/JEIM-02-2014-0017

50. Alharbi F, Atkins A, Stanier C (2016) Understanding the determinants of cloud computing adoption in Saudi healthcare organizations. Complex Intell Syst 2:155-171. https://doi.org/10.1007/ s40747-016-0021-9

51. Adiyasa H, Hidayanto AN, Pinem AA, Solikin NES, Putri PBM (2018) Exploring the factors for cloud computing adoption in Indonesia. In: Proceedings of International Conference on Computing, Engineering, and Design, 2018, pp 137-142. IEEE. https://doi.org/10.1109/ICCED.2018.00035

52. Khayer A, Talukder MS, Bao Y, Hossain MN (2019) Cloud computing adoption and its impact on SMEs' performance for cloud supported operations: a dual-stage analytical approach. Technol Soc 60:1-36. https://doi.org/10.1016/j.techsoc.2019.101225

53. Ali O, Shrestha A, Osmanaj V, Muhammed S (2020) Cloud computing technology adoption: an evaluation of key factors in local governments. Inf Technol People 34(2):1-38. https://doi.org/10.1108/ ITP-03-2019-0119

54. Shahzad F, Xiu G, Khan I, Shahbaz M, Riaz MU, Abbas A (2020) The moderating role of intrinsic motivation in cloud computing adoption in online education in a developing country: a structural equation model. Asia Pac Educ Rev 21:121-141. https://doi.org/10.1007/s12564-019-09611-2

55. El-Haddadeh R (2020) Digital innovation dynamics influence on organizational adoption: the case of cloud computing services. Inf Syst Front 22:985-999. https://doi.org/10.1007/s10796-019-09912-2

56. Bhardwaj AK, Garg L, Garg A, Gajpal Y (2021) E-learning during COVID-19 outbreak: cloud computing adoption in Indian public universities. Comput, Mater Continua 66(3):2471-2492. https://doi. org/10.32604/cmc.2021.014099

57. Sharma SK, Al-Badi AH, Govindaluri SM, Al-Kharusi MH (2016) Predicting motivators of cloud computing adoption: a developing country perspective. Comput Hum Behav 62:61-69. https://doi.org/ 10.1016/j.chb.2016.03.073

58. Alotaibi MB (2016) Antecedents of software-as-a-service (SaaS) adoption: a structural equation model. Int J Adv Comput Res 6(25):114-129. https://doi.org/10.19101/JJACR.2016.626019 
59. Amin R, Inayat I, Shahzad B, Saleem K, Aijun L (2017) An empirical study on acceptance of secure healthcare service in Malaysia, Pakistan, and Saudi Arabia: a mobile cloud computing perspective. Ann Telecommun 72:253-264. https://doi.org/10.1007/s12243-016-0553-4

60. Sallehudin H, Aman AHM, Razak RC, Ismail M, Bakar NAA, Fadzil AFM, Baker R (2020) Performance and key factors of cloud computing implementation in the public sector. Int $\mathrm{J}$ Bus Soc 21(1):134-152. https://doi.org/10.33736/ijbs.3231.2020

61. Asadi Z, Abdekhoda M, Nadrian H (2020) Cloud computing services adoption among higher education faculties: development of a standardized questionnaire. Educ Inf Technol 25:175-191. https://doi.org/ 10.1007/s10639-019-09932-0

62. Fretschner M, Clauss T, Hagenau T, Lüthje C (2021) CEOs' search for alignment: the impact of strategic orien- tations on an extended adoption of software as-a-service in SME. Technol Anal Strateg Manage. https://doi.org/10.1080/09537325.2021.1915477

63. Low C, Chen Y, Wu M (2011) Understanding the determinants of cloud computing adoption. Ind Manag Data Syst 111(7):1006-1023. https://doi.org/10.1108/02635571111161262

64. Hsu PF, Ray S, Li-Hsieh YY (2012) Cloud computing as an innovation: perception, attitude, and adoption. Int J Inf Manage 32(6):533-540. https://doi.org/10.1016/j.ijinfomgt.2012.04.001

65. Hsu PF, Ray S, Li-Hsieh YY (2014) Examining cloud computing adoption intention, pricing mechanism, and deployment model. Int J Inf Manage 34(4):474-488. https://doi.org/10.1016/j.ijinfomgt.2014. 04.006

66. Alotaibi MB (2014) Exploring users' attitudes and intentions toward the adoption of cloud computing in Saudi Arabia: an empirical investigation. J Comput Sci 10(11):2315-2329. https://doi.org/10.3844/ jessp.2014.2315.2329

67. Jeyaraj A, Rottman JW, Lacity MC (2006) A review of the predictors, linkages, and biases in IT innovation adoption research. J Inf Technol 21(1):1-23. https://doi.org/10.1057/palgrave.jit.2000056

68. MacLennan E, Van Belle JP (2014) Factors affecting the organizational adoption of service-oriented architecture (SOA). IseB 12(1):71-100. https://doi.org/10.1007/s10257-012-0212-X

69. Rhee HS, Riggins FJ, Kim C (2009) The impact of product type and perceived characteristics of the web on multifaceted online shopping behavior. J Organ Comput Electron Commer 19(1):1-29. https:// doi.org/10.1080/10919390802198907

70. Lee Y, Larsen KR, Han HJ (2009) Threat or coping appraisal: determinants of SMB executives' decision to adopt anti-malware software. Eur J Inf Syst 18(2):177-187. https://doi.org/10.1057/ejis.2009.11

71. Chae HC, Koh CE, Park KO (2018) Information technology capability and firm performance: role of industry. Inf Manage 55(5):525-546. https://doi.org/10.1016/j.im.2017.10.001

72. Dimitriadis S, Kyrezis N (2011) The effect of trust, channel technology, and transaction type on the adoption of self- service bank channels. Serv Ind J 31(8):1293-1310. https://doi.org/10.1080/02642 060903437576

73. Choi H, Kim Y, Kim J (2011) Driving factors of post adoption behavior in mobile data services. J Bus Res 64(11):1212-1217. https://doi.org/10.1016/j.jbusres.2011.06.025

74. Arpaci I (2016) Understanding and predicting students' intention to use mobile cloud storage services. Comput Hum Behav 58:150-157. https://doi.org/10.1016/j.chb.2015.12.067

75. Sintonen S, Immonen M (2013) Telecare services for aging people: assessment of critical factors influencing the adoption intention. Comput Hum Behav 29(4):1307-1317. https://doi.org/10.1016/j.chb. 2013.01.037

76. Gupta P, Seetharaman A, Raj JR (2013) The usage and adoption of cloud computing by small and medium businesses. Int J Inf Manage 33(5):861-874. https://doi.org/10.1016/j.ijinfomgt.2013.07.001

77. Behrend TS, Wiebe EN, London JE, Johnson EC (2011) Cloud computing adoption and usage in community colleges. Behav Inf Technol 30(2):231-240. https://doi.org/10.1080/0144929X.2010.489118

78. Yousafzai SY, Foxall G, Pallister J (2009) Multi-dimensional role of trust in Internet banking adoption. Serv Ind J 29(5):591-605. https://doi.org/10.1080/02642060902719958

79. Goode S, Lin C, Tsai JC, Jiang JJ (2015) Rethinking the role of security in client satisfaction with Software-as-a- Service (SaaS) providers. Decis Support Syst 70:73-85. https://doi.org/10.1016/j.dss.2014. 12.005

80. Shaw N (2015) The mediating role of perceived security: an empirical study of mobile wallet adoption in USA. In: Proceedings of International Conference on HCI in Business, 2015, vol. 9191, pp 358-369. Springer. https://doi.org/10.1007/978-3-319-20895-4_33

81. Dutot V (2015) Factors influencing near field communication (NFC) adoption: an extended TAM approach. J High Technol Manage Res 26(1):45-57. https://doi.org/10.1016/j.hitech.2015.04.005 
82. Lee SG, Chae SH, Cho KM (2013) Drivers and inhibitors of SaaS adoption in Korea. Int J Inf Manage 33(3):429-440. https://doi.org/10.1016/j.ijinfomgt.2013.01.006

83. Demirhan D, Jaco V, Raghunatha S (2002) Strategic IT investments: impact of switching cost and declining technology cost. In: Proceedings of 23th International Conference on Information Systems, 2002, pp 469-480. AIS Electronic Library

84. Lim J, Richardson VJ, Roberts TL (2004) Information technology investment and firm performance: a meta-analysis. In: Proceedings of 37th Annual Hawaii International Conference on System Sciences, 2004, pp 1-10. IEEE

85. Zhu Y, Li Y, Wang W, Chen J (2010) What leads to post-implementation success of ERP? An empirical study of the Chinese retail industry. Int J Inf Manage 30(3):265-276. https://doi.org/10.1016/j.ijinfomgt. 2009.09.007

86. UN (2018) UN E-Government Survey. https://www.un.org/development/desa/publications/2018-un-egovernment-survey.html. Accessed 10 June 2021

87. Lee JD, Kim W, Kim TY (2003) The role of IT, R\&D in industrial productivity growth: evidence from Korea. In: Proceedings of Evaluation of Government Funded R\&D Activities Conference, 2003, pp 1-17. ZEW

88. Henseler J, Ringle CM, Sarstedt M (2016) Testing measurement invariance of composites using partial least square. Int Mark Rev 33(3):405-431. https://doi.org/10.1108/IMR-09-2014-0304

89. Im I, Kim Y, Han HJ (2008) The effects of perceived risk and technology type on users' acceptance of technologies. Inf Manage 45(1):1-9. https://doi.org/10.1016/j.im.2007.03.005

90. Sun P, Wang X (2012) Application of ant colony optimization in preventive software maintenance policy. In: Proceedings of International Conference on Information Science and Technology, 2012, pp 141-144. IEEE. https://doi.org/10.1109/ICIST.2012.6221624

91. Statista (2019) South Korea: internet penetration 2000-2018. URL https://www.statista.com/statistics/ 255859/internet-penetration-in-south-korea/. Accessed 10 June 2021

92. Statista (2020) Internet usage in South Korea. URL https://www.statista.com/topics/2230/internetusage-in-south-korea/. Accessed 10 June 2021

93. Ciganek AP, Haseman WD, Ramamurthy K (2014) Time to decision: the drivers of innovation adoption decisions. Enterp Inf Syst 8(2):279-308. https://doi.org/10.1080/17517575.2012.690453

94. Oskarsso G (2009) Information technology capabilities and their impact on the transfer of external information. Rev Polit Adm 5(2):335-361

95. Xue Y, Liang H, Boulton WR (2008) Information technology governance in information technology investment decision processes: the impact of investment characteristics, external environment, and internal context. MIS Q 32(1):67-96. https://doi.org/10.2307/25148829

96. Al-Dwairi RM, Al-Tweit N, Zyout K (2018) Factors influencing cloud-computing adoption in small and medium E-commerce enterprises in Jordan. In: Proceedings of International Conference on Internet and e-Business, 2018, pp 73-78. ACM. https://doi.org/10.1145/3230348.3230370

Publisher's Note Springer Nature remains neutral with regard to jurisdictional claims in published maps and institutional affiliations.

\section{Authors and Affiliations}

\section{Chi-hoon Song ${ }^{1}$ (D) Y Young-woo Sohn ${ }^{1,2}$}

Chi-hoon Song

chihoon@postech.ac.kr

Young-woo Sohn

ywsohn@postech.ac.kr

1 Department of Convergence IT Engineering, Pohang University of Science and Technology, 77 Cheongam-ro, Pohang, Gyeongbuk 37673, South Korea

2 Graduate School of Artificial Intelligence, Pohang University of Science and Technology, 77 Cheongam-ro, Pohang, Gyeongbuk 37673, South Korea 